\title{
Rituales funerarios neolíticos, calcolíticos y de la Edad del Bronce en la provincia de Ciudad Real: Cerro Ortega (Villanueva de la Fuente) y Castillejo del Bonete (Terrinches) Neolithic, Chalcolithic and Bronze Age funeral rituals in the province of Ciudad Real: Cerro Ortega (Villanueva de la Fuente) and Castillejo del Bonete (Terrinches)
}

\author{
Luis Benítez de Lugo Enrich ${ }^{1}$
}

\begin{abstract}
Resumen
Este trabajo expone datos y materiales inéditos sobre dos yacimientos arqueológicos funerarios fundamentales para entender los procesos de cambio cultural sucedidos entre mediados del IV y mediados del I milenios cal AC en el sur de la Meseta: el abrigo del Cerro Ortega y los túmulos de Castillejo del Bonete. La presencia de componentes tales como ídolos, cerámicas del tipo Dornajos, adornos personales de variscita, marfil, concha o hueso, así como su orientación a eventos astronómicos, aporta información acerca de los aspectos simbólicos de las primeras comunidades productoras de La Mancha y Campo de Montiel. También de los procesos que derivarán en la organización de las primeras sociedades complejas de la región, que en modo alguno fue 'un vacío' en estas épocas. El estudio permite observar cómo han evolucionado las pautas funerarias durante la Prehistoria reciente en la cuenca alta del río Guadiana hasta la Cultura de las Motillas, también conocida como Bronce de La Mancha.
\end{abstract}

Palabras clave: Arqueología prehistórica, Arqueología funeraria, Alto Guadiana, Calcolítico, Neolítico, Castilla-La Mancha.

\begin{abstract}
This work presents unpublished data and materials on two fundamental archaeological funerary sites to understand the processes of cultural change between the middle of the $\mathrm{IV}^{\text {th }}$ and the middle of the $\mathrm{I}^{\text {st }}$ millennium BC to the South of the Iberian Plateau: the shelter of Cerro Ortega and the tumuli of Castillejo del Bonete. The presence in both sites of pieces such as idols, pottery of the Dornajos type, personal adornments of variscite, ivory, shell or bone, as well as their orientation to astronomical events, provides information about the symbolic aspects of the first producing communities of La Mancha and Campo de Montiel. The data provided also gives information about the processes that will result in the organization of the first complex societies of the region, which in no way was 'a vacuum' in these times. The study allows us to observe how funerary patterns have evolved during the recent Prehistory in the upper basin of the Guadiana River, until culminating in the formation of the Culture of the Motillas, also known as Bronze Age of La Mancha.
\end{abstract}

Keywords: Prehistoric Archaeology, Recent Prehistory, South Iberian Plateau, Chalcolithic, Neolithic, Castilla-La Mancha.

\section{InTRODUCCIÓN}

El estudio acerca de las primeras sociedades productoras de la cuenca alta del río Guadiana está aún pendiente de desarrollo. A la ausencia de proyectos de investigación significados se une la escasez de los datos publicados.

La información más relevante procede del muy reducido número de yacimientos arqueológicos que han sido objeto de excavación científica. La tipología de los lugares estudiados es diversa. A diferencia de lo que sucede al sur de Sierra Morena, en la cuenca del Tajo, en la Meseta norte y en otras áreas peninsulares, el Neolítico y la Edad del Cobre en el Alto Guadiana se encuentran hasta el momento pendientes de una visión de conjunto que

Departamento de Prehistoria y Arqueología. Universidad Autónoma de Madrid. luis.benitezdelugo@uam.es. http://orcid.org/0000-00032000-6293 


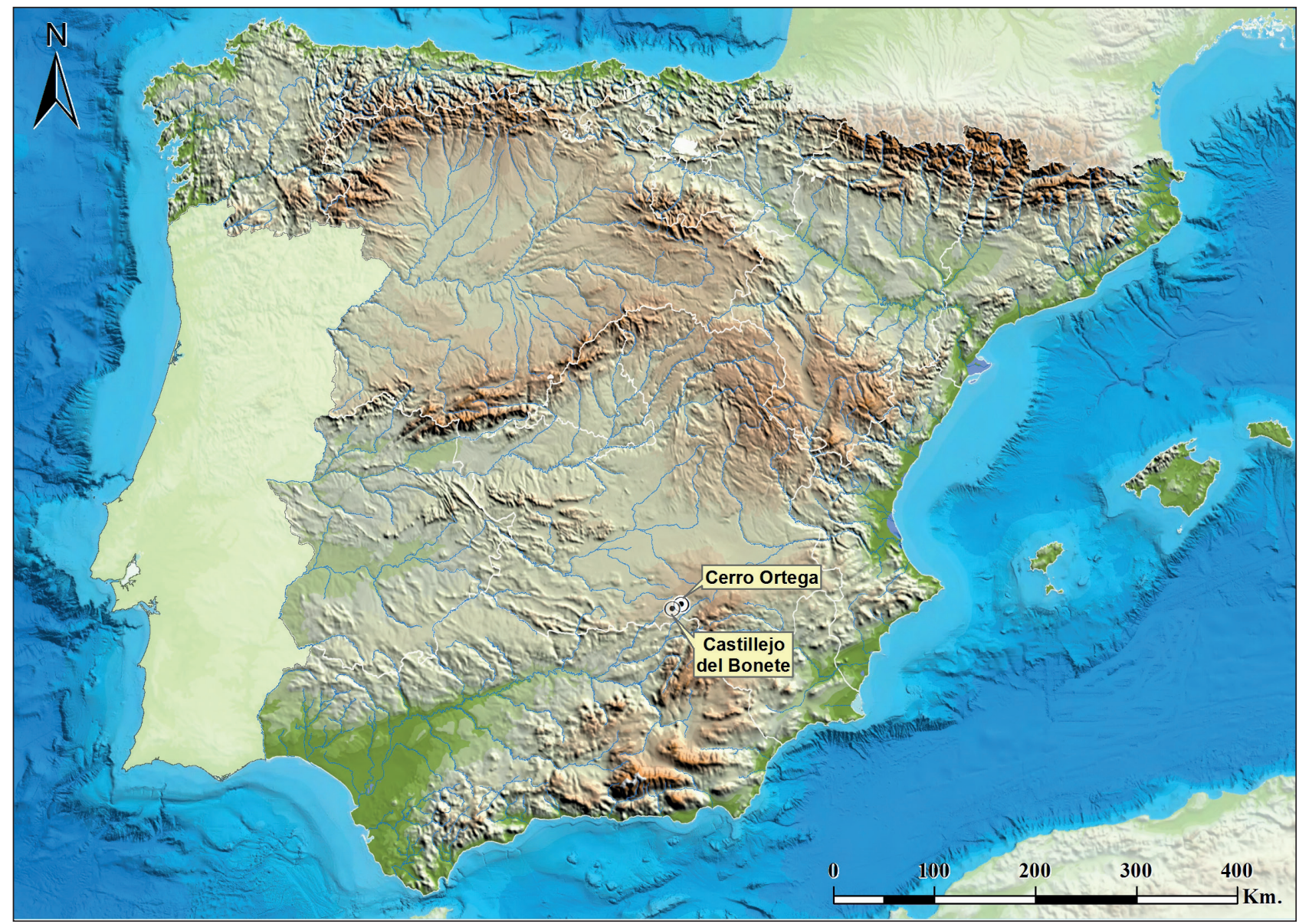

Figura 1. Mapa general de localización

permita sentar las bases para su adecuada caracterización. Este trabajo presenta y contextualiza culturalmente dos yacimientos arqueológicos que resultan fundamentales para entender los procesos de cambio social sucedidos al sur de la Meseta desde el Neolítico final hasta el Bronce Pleno, ya durante la Cultura de las Motillas: Cerro Ortega y Castillejo del Bonete (fig. 1).

\section{El abrigo sepulcral del Cerro Ortega (Villanueva de la Fuente, Ciudad Real)}

Los primeros resultados de las excavaciones arqueológicas desarrolladas al pie del Cerro Ortega fueron presentados en la reunión científica sobre el Patrimonio Arqueológico de Ciudad Real, organizada por la UNED (Barrio Aldea y Maquedano Carrasco, 2000). En este yacimiento se descubrió un depósito de huesos humanos mezclados con abundantes restos de fauna y algunos elementos de ajuar, enterrados en un abrigo que había colapsado por el paso del tiempo. La erosión provocada por la escorrentía que discurre sobre su visera provocó la caída de bloques de roca (fig. 2).

El yacimiento ha sido adscrito tanto a la Edad del Cobre (Barrio Aldea y Maquedano Carrasco, 2000) como al Neolítico (Gil Pitarch et al., 1999; Polo Cerdá et al., 1999). En 2016 se publicó una primera datación absoluta de este yacimiento, que proporciona fechas de finales del IV milenio cal AC, correspondientes a un momento cultural de transición entre las primeras sociedades agrarias y las primeras metalúrgicas: $3341-3027$ cal AC (2 $\sigma)$ (Odriozola Lloret et al., 2016). En este yacimiento no se ha encontrado metal.

Todo el frente rocoso en donde se encontraba el abrigo es de areniscas rojas. Es de interés señalar que junto al lugar de enterramiento existe un estrato de margas muy visible, que llama poderosamente la atención por su tonalidad verdosa, claramente diferente del entorno mayoritario.

Los restos humanos fueron depositados en este lugar sin conexión anatómica, como última etapa de un programa mortuorio desarrollado en sus primeras fases en otros lugares. Aunque es preciso insistir en que este abrigo ha sido sometido a alteraciones postdeposicionales severas, no es menos cierto que no debe sorprender un enterramiento colectivo secundario en el Neolítico final del interior de la Península. Existen otros casos claros de esta clase, como sucede en El Rebolosillo (Torrelaguna, Madrid), donde fueron enterrados un mínimo de 21 individuos de todas las edades y sexos (Díaz del Río et al., 2017). En Cerro Ortega se han documentado acumulaciones selectivas de huesos, 


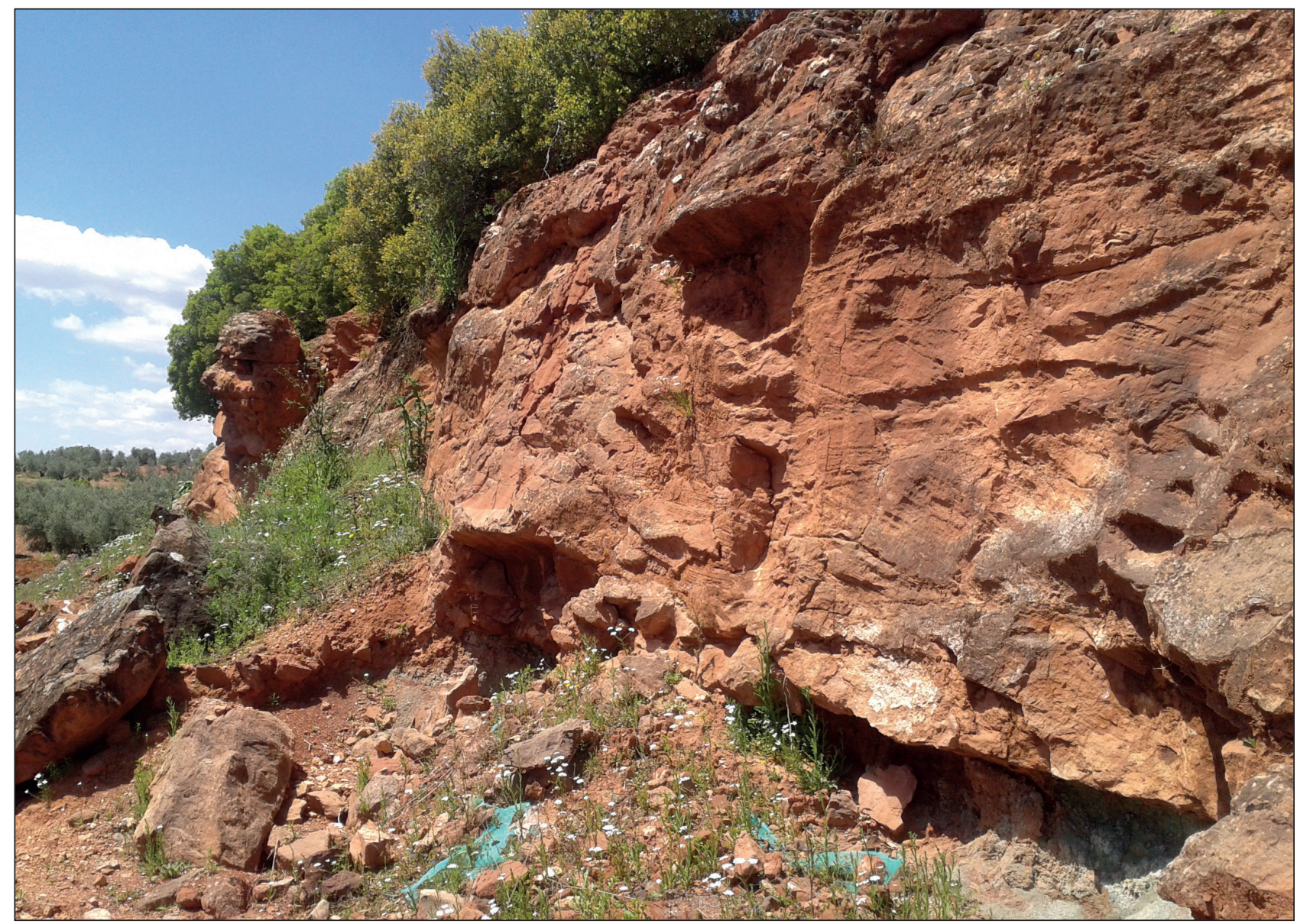

Figura 2. Cerro Ortega: vista exterior general del abrigo colapsado, con el frente de arenisca roja y una veta de margas verdosas asociadas a los enterramientos. Vista desde el sureste.

distribuidas de forma intencionada: los huesos largos en una zona y los cráneos en otra (bajo la visera del abrigo). Los estudios antropológicos publicados revelaron el enterramiento en este lugar de un mínimo de 19 individuos; 12 de ellos adultos ( 7 mujeres y 5 hombres). Su esperanza de vida media era de 40 años. La estatura de los hombres oscilaba entre 1,62 y 1,79 m, mientras que la de las mujeres era de entre 1,44 y $1,51 \mathrm{~m}$. Otros siete individuos eran niños o jóvenes; desde recién nacidos hasta personas de 15 ó 16 años. Algunos de los individuos presentaban patologías como entesopatías derivadas de grandes esfuerzos, espondialoartrosis, evidencias de reuma y de tumoraciones craneales producidas por hematomas calcificados. Algunos de los huesos humanos largos podrían presentar huellas de descarnamiento (Gil Pitarch et al., 1999: 390). Los datos paleonutricionales indican una dieta agrícola vegetariana, con un aporte ocasional de proteína animal. Evidencias de hipoplasia dental revelan períodos de mala nutrición (Polo Cerdá et al., 1999).

El hallazgo de aproximadamente 200 fragmentos de huesos de animales -algunos con fracturas en el hueso fresco destinadas probablemente a extraer la médula-, encontrados junto a algunos carbones, pueden estar revelando la práctica de ritos de comensalidad cerca del lugar del enterramiento, más que ser producto del incendio de una estructura lígnea construida dentro del abrigo similar a la documentada para albergar el enterramiento múltiple primario de Cueva Maturras (Argamasilla de Alba, Ciudad Real) (Gutiérrez Sáez et al., 2002; Ocaña et al. 2015). Los huesos humanos de Cerro Ortega no están quemados.

La presencia de fragmentos de cerámica elaborada a mano puede estar en relación con esas prácticas (fig. 3). Entre las piezas destacan un borde con decoración incisa interna y externa, que podría ser adscrito -sin otra dificultad que la cronológica- a la clase Dornajos (fig. 3.3), así como una ollita de borde entrante y mamelón perforado (fig. 3.1). Hay que recordar que las cerámicas del grupo Dornajos están en uso hasta bien entrado en II mileno cal AC, si bien no se conoce con exactitud el inicio de su utilización. Esta importante cuestión será tratada más adelante.

En asociación con los huesos humanos fue encontrada una notable colección de largas varillas de hueso trabajado, apuntadas en su extremo distal (fig. 4). Especialmente significativas resultan dos de ellas, por la decoración que presentan en el extremo proximal. Una de ellas cuenta con decoración idoliforme organizada en dos cuerpos: el primero es triangular y se sitúa al extremo, mientras que el segundo es cuadrangular y sirve de transición entre la cabeza de la aguja y el fuste, cuyos bordes tienden a ser rectos (fig. 4.6). El antropomorfo de cuerpo triangular es 


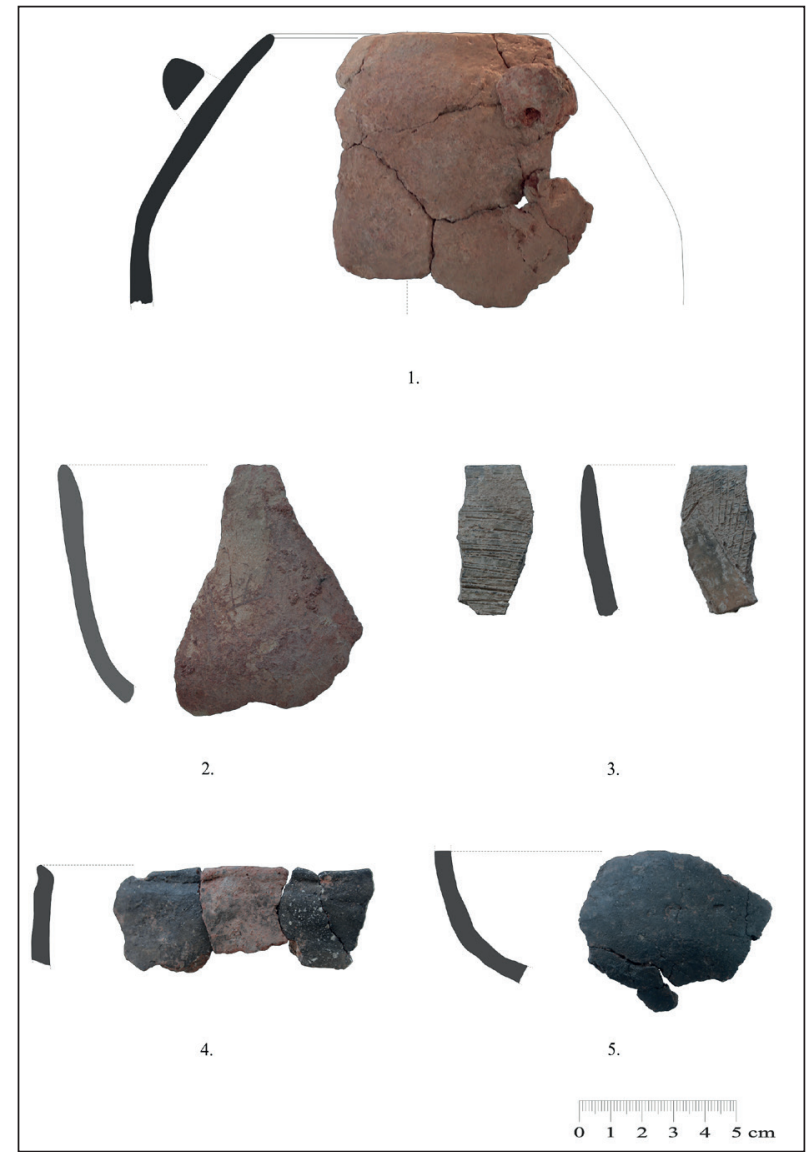

Figura 3. Cerro Ortega: cerámicas.

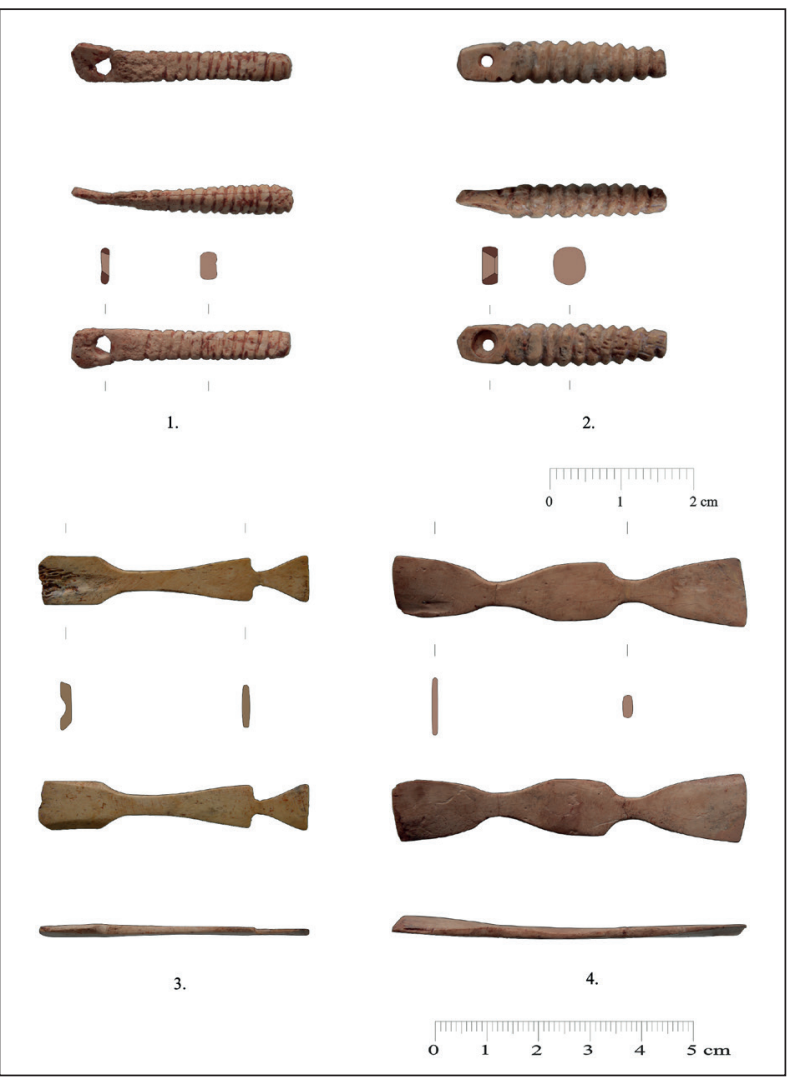

Figura 5. Cerro Ortega: industria ósea; adornos personales e idoliformes.

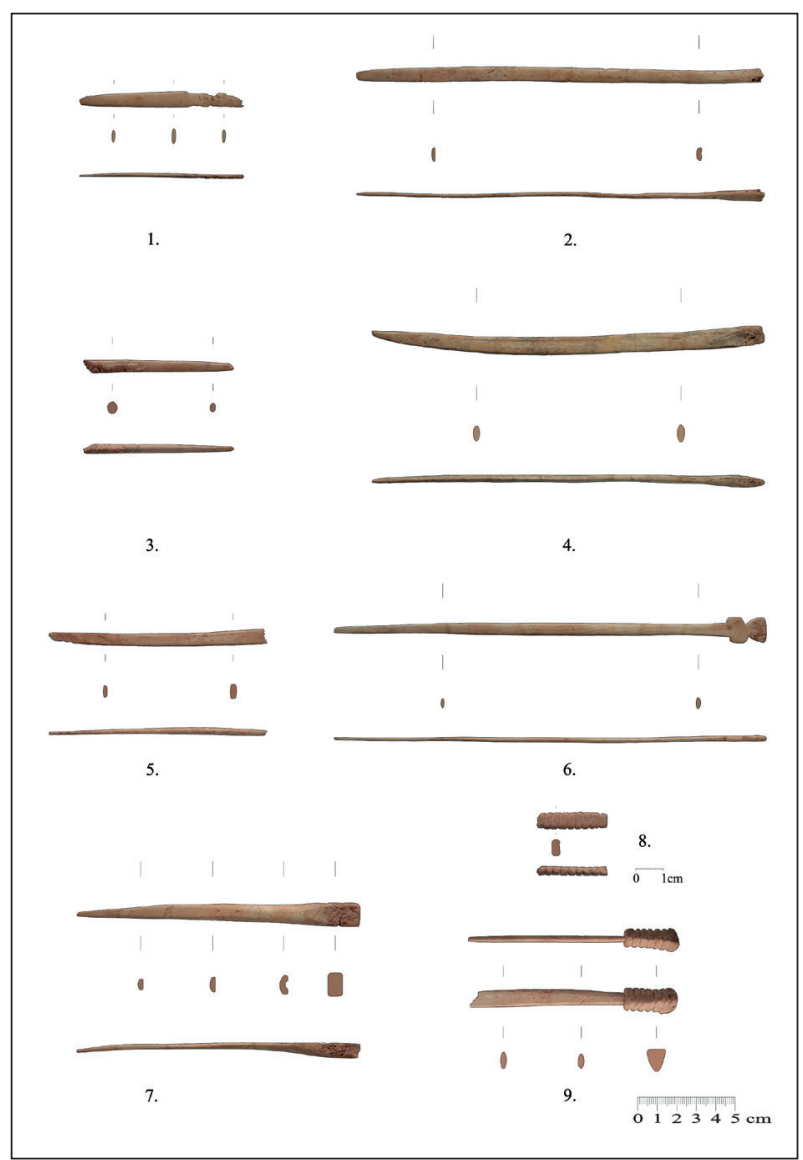

Figura 4. Cerro Ortega: industria ósea; varillas.

un argumento recurrente en la iconografía de la Prehistoria reciente peninsular; en la zona de estudio se encuentra en soporte mueble óseo en Castillejo del Bonete (vid. infra) y en pintura rupestre esquemática de tonos rojizos en el abrigo de El Retamoso, en Despeñaperros. La segunda varilla a destacar del Cerro Ortega no está completa, pero en su parte proximal dispone de un cuerpo engrosado de sección triangular con decoración ranurada acanalada (fig. 4.9). Pudiera ser que entre las materias primas empleadas para elaborar algunas de estas varillas se utilizara de pata de flamenco. Es un ave que frecuenta las lagunas manchegas (hemos tenido ocasión de verlas en Moral de Calatrava, a unos $90 \mathrm{~km}$ de este lugar); sus pollos son fáciles de capturar hasta que son capaces de volar. También se han encontrado entre las piezas de ajuar varios colgantes y dos ídolos elaborados en hueso (fig. 5). Los ídolos son de placa con sección plana. Ambos tienen dos pares de escotaduras que dan lugar, en cada pieza, a tres cuerpos de forma aproximadamente triangular. En uno de ellos se aprecia una sección ligeramente cóncava en uno de los cuerpos; probablemente se debe a un resto del canal medular del hueso utilizado como materia prima (fig 5.3). Los colgantes son de cuerpo rectangular y tienen diferentes secciones -uno cuadrangular; el otro tendente al círculo-; su fuste cuenta con decoración segmentada acanalada y las perforaciones son cilíndrica en un caso y cónica en el otro. 


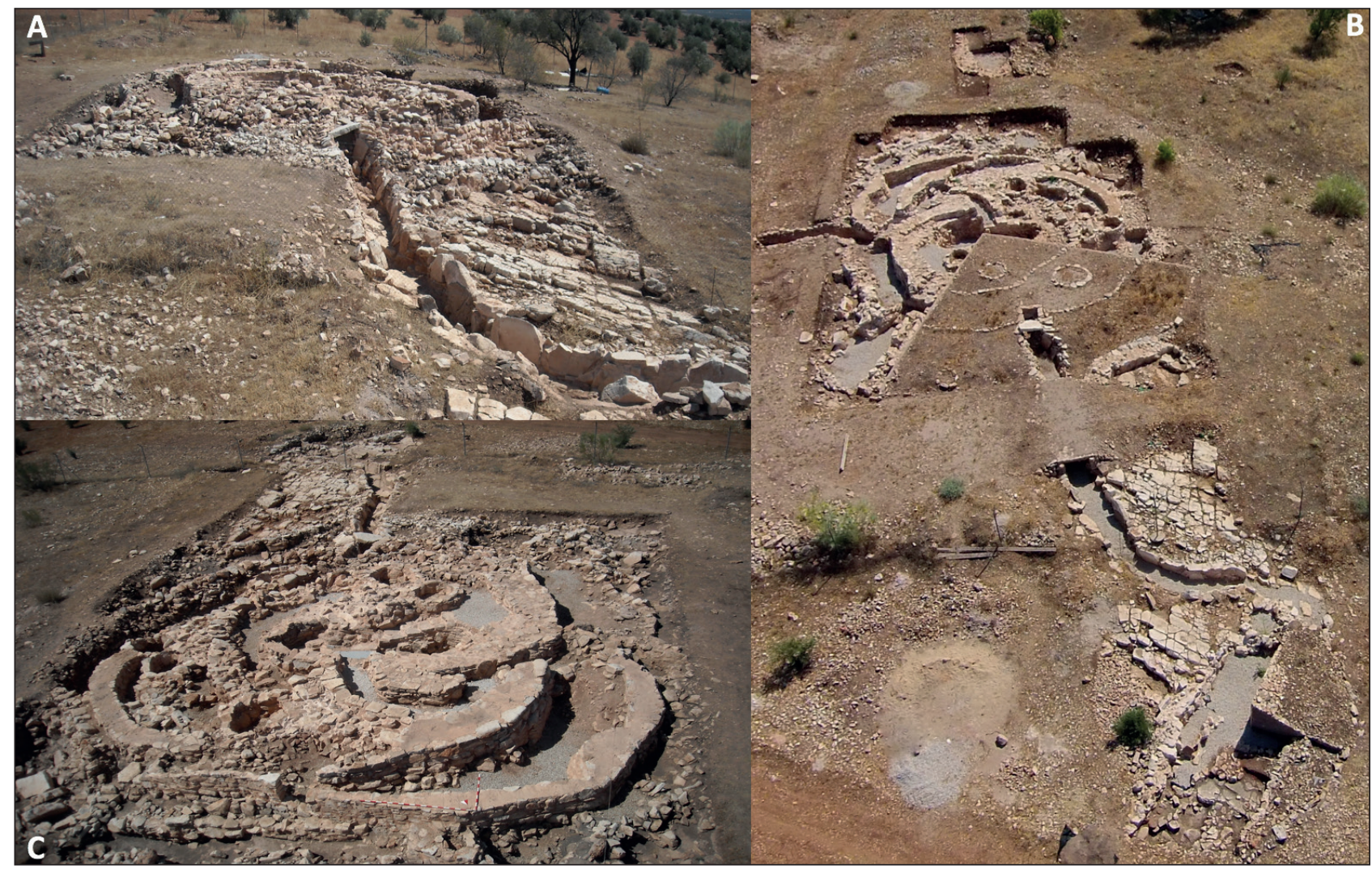

Figura 6. Castillejo del Bonete. Vista aérea del monumento tumular. El Túmulo 2 se encuentra en la esquina inferior derecha de la fotografía B.

Asimismo, fueron recuperadas en este abrigo varias cuentas, tanto de arcilla como de otros minerales: pizarra, clinocloro, clinoferrosilita y calcita (Odriozola et al., 2016). No menos relevantes son los útiles de sílex amortizados en esta necrópolis: diez puntas de flecha con pedúnculo y aletas y, especialmente, nueve láminas con una longitud máxima de $17 \mathrm{~cm}$, algunas con el filo retocado (Benítez de Lugo y Esteban, 2018). Todos los materiales fueron encontrados juntos y acumulados en la misma unidad estratigráfica antes descrita, junto a los huesos humanos.

En este yacimiento se ha llevado a cabo un estudio arqueoastronómico (ibidem). Al no existir estructuras medibles, salvo las aberturas (ya muy derrumbadas) y de escasa profundidad del abrigo, la investigación se centró en determinar la orientación general de la pared rocosa en la que se encuentran y a realizar el análisis del horizonte. Es interesante señalar que la dirección perpendicular a la pared rocosa, justo en el lugar donde se encuentran las tumbas, apunta a un intervalo de acimut comprendido entre $125^{\circ}$ y $128^{\circ}$ que, proyectado sobre el horizonte local y considerando su altura, engloba el punto donde se produce el orto del solsticio de invierno, que coincide con una de las cumbres de la cercana Sierra del Relumbrar, situada en tercer (y último) plano y a unos $4 \mathrm{~km}$ de distancia. La pared rocosa presenta distintas orientaciones a lo largo de toda su extensión, pero las tumbas se excavaron precisamente en la zona donde la entrada de las tumbas se orienta hacia dicho evento astronómico. Aunque este hecho, por sí solo, podría considerarse casual, el que coincida con la orientación astronómica principal de otros yacimientos próximos, como sucede de forma muy significativa en Castillejo del Bonete (vid. infra), es una base para proponer que el orto solar en el solsticio de invierno fue un factor tenido en cuenta en rituales funerarios de La Mancha durante la Prehistoria reciente.

\section{Túmulos y Cueva funeraria de Castillejo del Bonete (Terrinches, Ciudad Real)}

Las excavaciones arqueológicas en Castillejo del Bonete comenzaron en $2003 \mathrm{y}$, de forma singular en el panorama investigador existente, permanecen activas hoy (Benítez de Lugo et al., 2014-2015). A lo largo de este tiempo se ha fraguado un proyecto cofinanciado sistemáticamente por el Ayuntamiento de Terrinches y la Junta de Comunidades de Castilla-La Mancha mediante convocatorias competitivas regionales de ayudas a la investigación, que ha permitido generar conocimiento y abundante literatura científica (Benítez de Lugo et al., 2014b). En 2014 este enclave fue declarado Bien de Interés Cultural. Las excavaciones, que han abierto por el momento un área próxima a $850 \mathrm{~m}^{2}$, han permitido descubrir un conjunto tumular prehistórico ceremonial sin igual, que fue utilizado, hasta donde hoy se sabe, durante un milenio y medio (fig. 6). Se localiza sobre el borde meridional de la Meseta Sur, justo en la ceja en donde ésta termina; en un lugar con amplio 


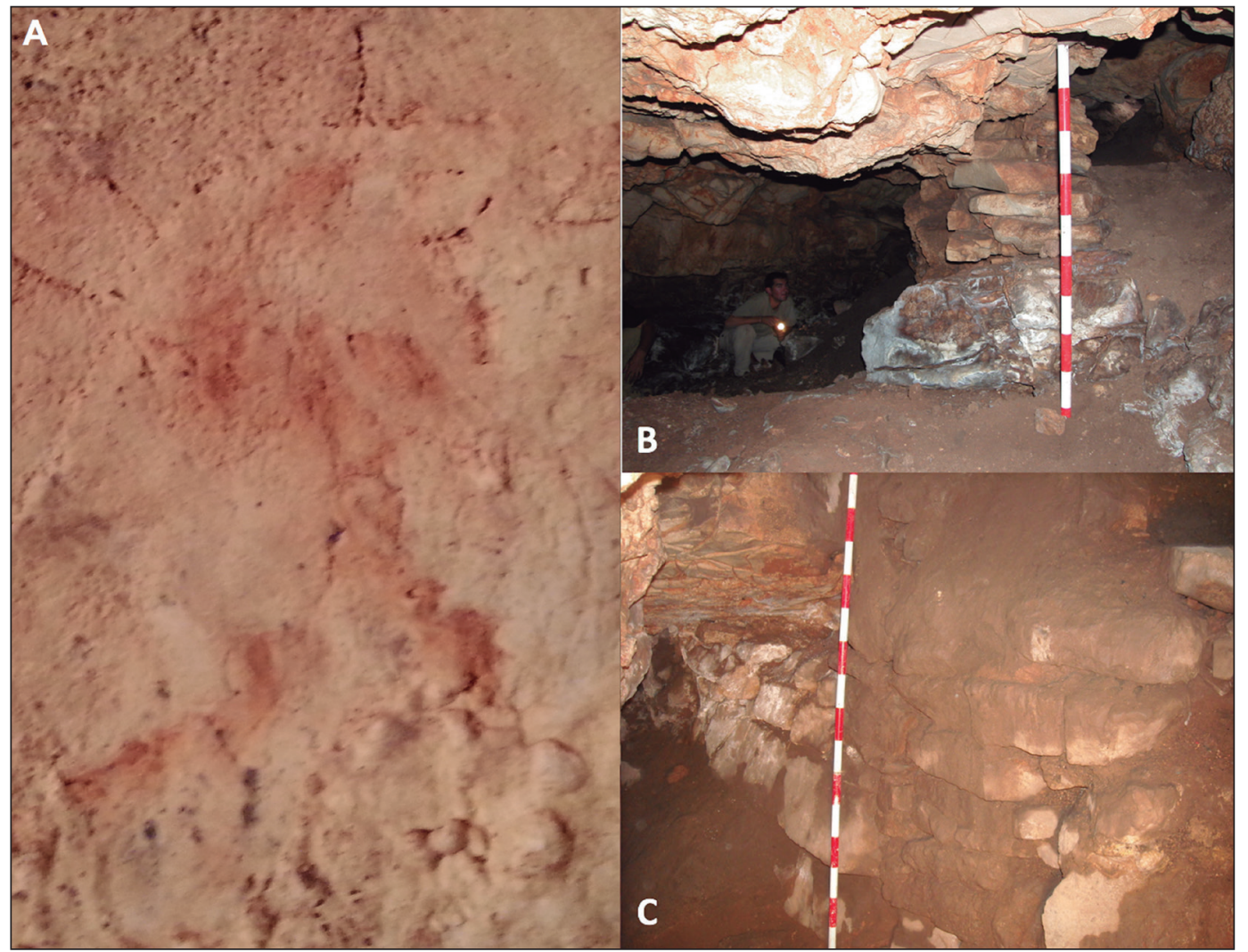

Figura 7. Castillejo del Bonete. Cueva: antropomorfo esquemático pintado en tonos rojizos (A) y construcciones de mampostería para organizar los espacios interiores (B y $C$ ).

horizonte despejado hacia el sur, de este a oeste. El sitio es muy visible para cualquiera que llegara a la Meseta desde el sur, este y oeste. A sus pies existe un corredor natural de paso entre la Meseta, la Alta Andalucía y Levante, por el cual discurrió la Vía de los Vasos de Vicarello muchos siglos después. Su carácter como marcador territorial parece claro. Este tipo de manifestación arquitectónica se levantó para transmitir un mensaje referido a la legitimación del derecho de un grupo a acceder y controlar los recursos (en este caso el territorio), utilizando como argumento los ancestros. Este proceso semiológico se observa también en el pozo de la motilla de El Azuer, que fue monumentalizado y rodeado con más de un centenar de tumbas dispuestas en torno al acceso al agua subterránea, dentro de una gran prominencia artificial que resultaba claramente visible desde la lejanía en la Llanura Manchega (Nájera et al., 2012).

En Castillejo del Bonete hasta el momento se han encontrado dos túmulos, aunque existen evidencias de otros que no han sido desenterrados aún. El túmulo principal, llamado Túmulo 1, es el más grande: su diámetro aproximado son $24 \mathrm{~m}$, y su altura $2,1 \mathrm{~m}$. Se ubica sobre una cueva natural utilizada como sepulcro, que presenta en su interior arte rupestre postpaleolítico esquemático (Polo Martín et al. 2015) y muros de mampostería trabada con barro, en ocasiones de varios metros de altura (fig. 7). La cueva cuenta con cuatro galerías, que han permanecido selladas e ignotas desde la Prehistoria hasta nuestros días.
Las tres primeras galerías de la cueva tienen una superficie de $65 \mathrm{~m}^{2}$. Además de los túmulos y la cueva existe un gran edificio singular y exento, cuya excavación aún no se ha completado, que fue construido dentro del complejo ceremonial y puesto al servicio del programa ritual aquí practicado. Este gran edificio singular, que tiene una anchura de $9 \mathrm{~m}$ y una longitud excavada (no finalizada) de $15 \mathrm{~m}$., se dedicó probablemente a la celebración de reuniones. No se han encontrado enterramientos en su interior. El Túmulo 1 cuenta con corredores abocinados y también corredores de comunicación con otros túmulos (fig. 8). El más largo de ellos -el Corredor 1- sirve para comunicar los túmulos 1 y 2; tiene 21,6 m de longitud, $0,75 \mathrm{~m}$ de anchura y una altura transitable de 1,30 m (Benítez de Lugo et al., 2014a: 159). Es interesante señalar que el Túmulo 1 no se compone sólo de una acumulación de tierra y piedras, dado que en el interior hay numerosos muros curvos similares a los característicos en una motilla (fig. 6C). Se trata de las evidencias de las sucesivas aperturas y cierres del cuerpo del túmulo a lo largo de su vida útil. Los materiales arqueológicos que se encuentran depositados en el lugar se localizan tanto en pequeños recintos como en más de treinta fosas o estructuras siliformes, que se han encontrado tanto vacías como con materiales arqueológicos de diferente clase en su interior (fig. 9). Estas estructuras sirvieron para realizar depósitos dentro del cuerpo del túmulo. En ocasiones están muy bien careadas; otras veces son simples agujeros, abiertos y vueltos a 


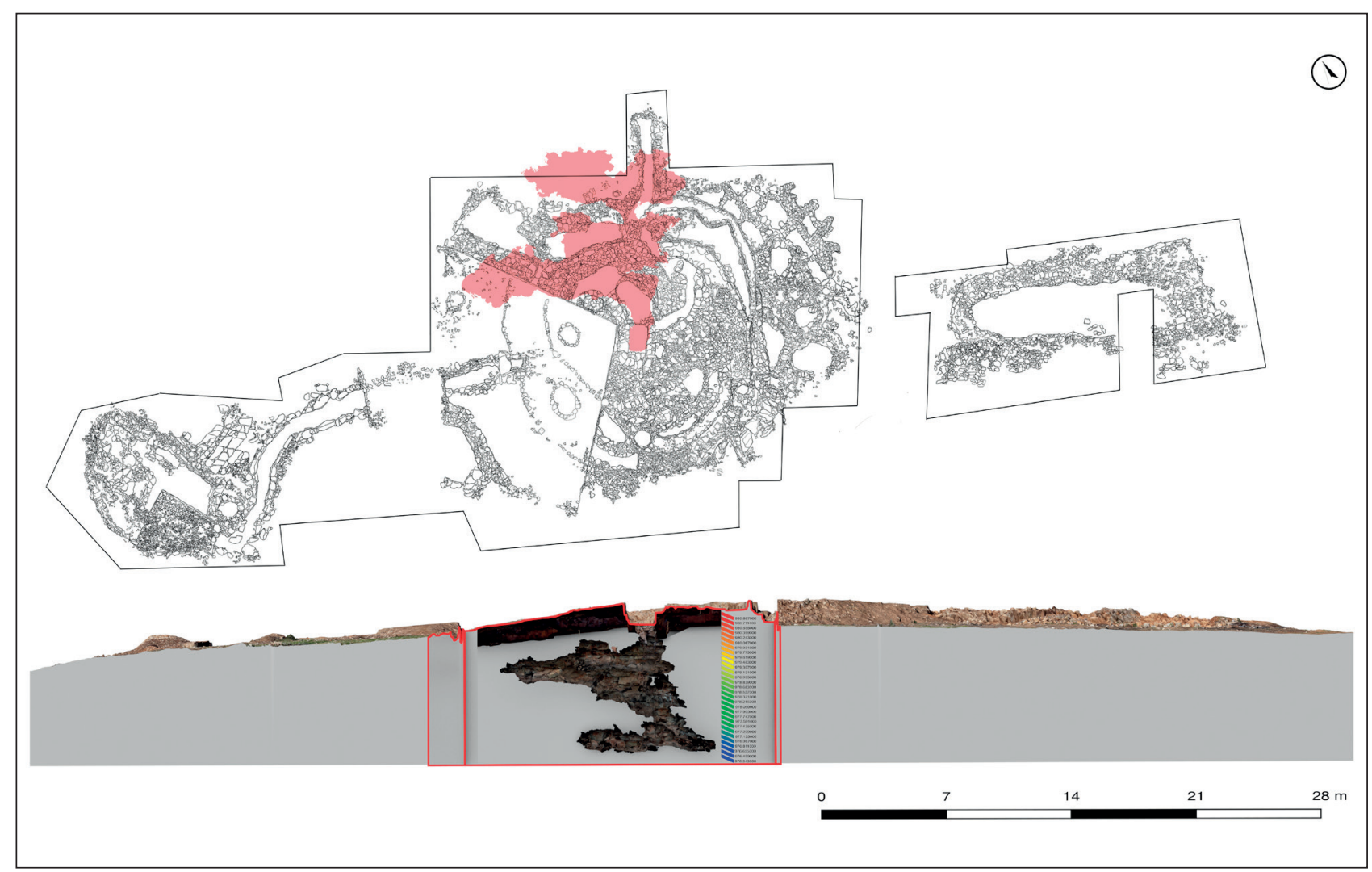

Figura 8. Castillejo del Bonete. Planta y sección de los túmulos, incluyendo la cueva descubierta bajo el Túmulo 1 (en el centro de la imagen), el Túmulo 2 (a la izquierda de la imagen) y el edificio singular exento localizado al este del complejo, denominado Recinto 4 (a la derecha de la imagen).

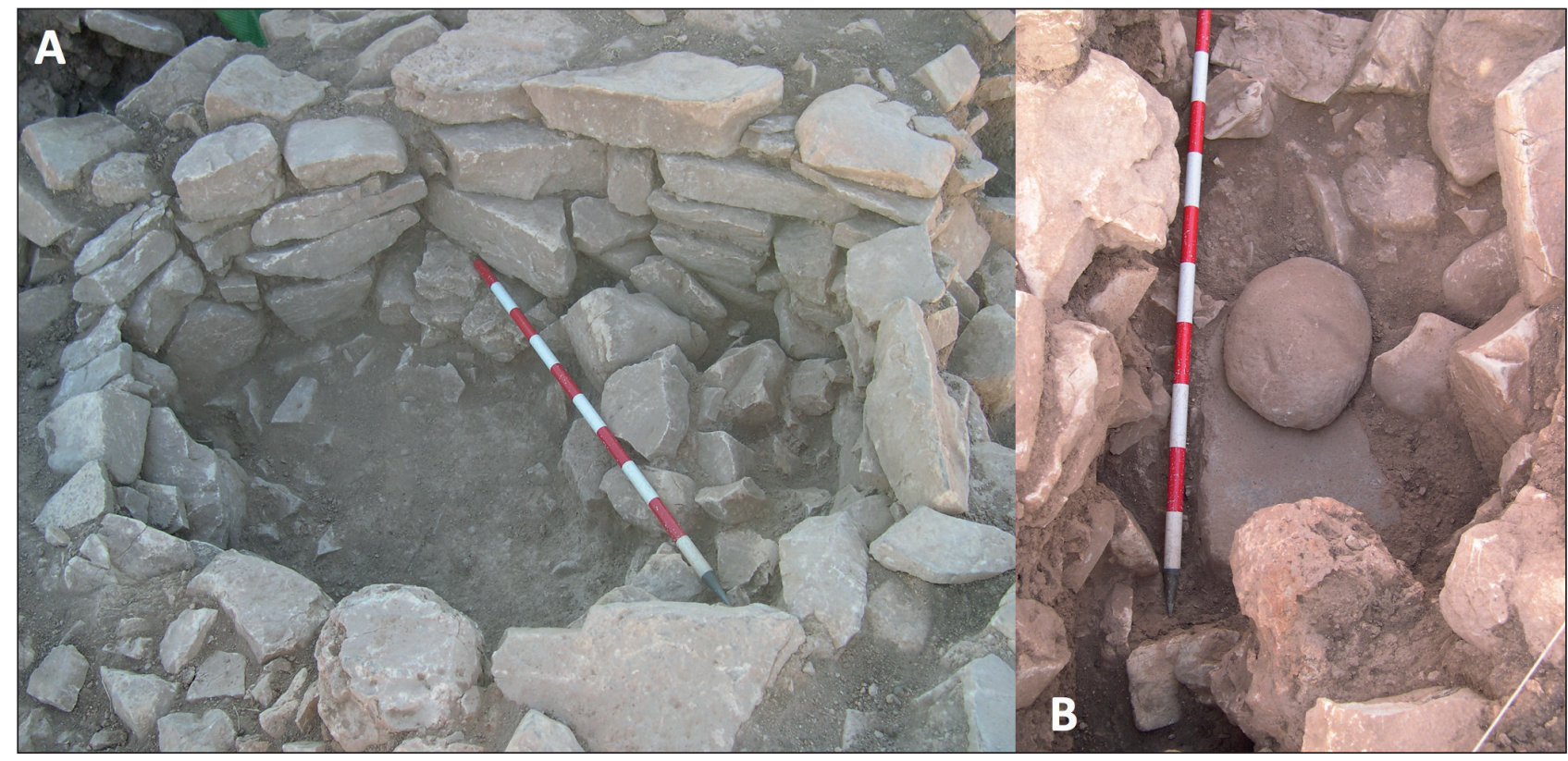

Figura 9. Castillejo del Bonete. Estructura siliforme para realizar depósitos (A). Molino barquiforme y mano moledera en posición primaria dentro de un depósito realizado en el cuerpo del túmulo principal (B).

rellenar con tierra y piedras tras ser usados; en ocasiones conservan en su posición original los objetos que fueron depositados en su interior antes de ser cubiertos nueva- mente de tierra y piedras (Benítez de Lugo et al., 2014a: 156 y 162). En Castillejo del Bonete se ha corroborado que estos depósitos obedecen a actos de entrega pautados 


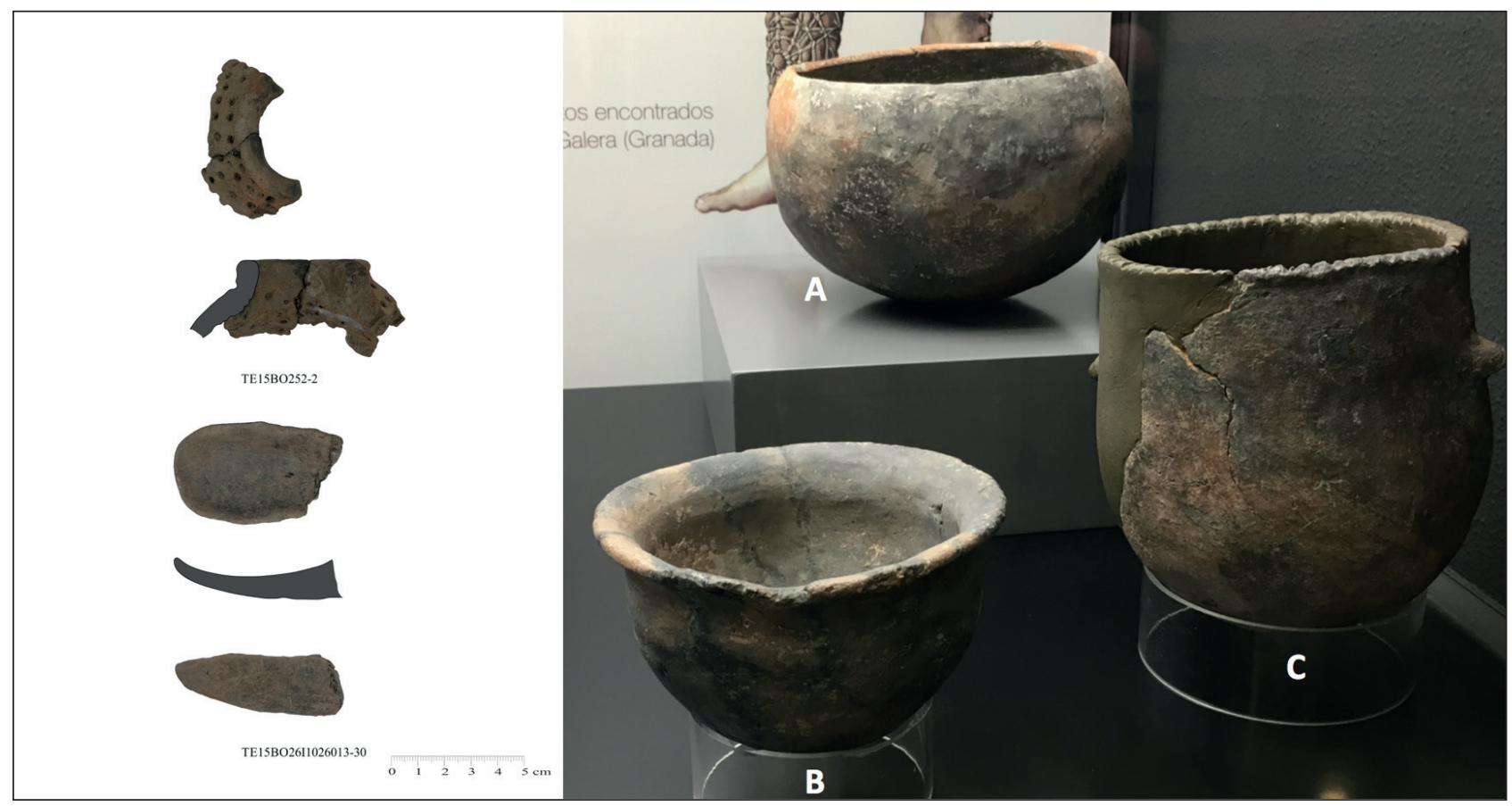

Figura 10. Castillejo del Bonete. Cerámica común depositada en el Museo de Ciudad Real. Izquierda: quesera y cuchara. Derecha: olla globular (A), vaso carenado (B) y vaso con labio decorado (C). Las piezas A y B fueron depositadas como ajuar dentro de la tumba 4. La pieza C se encontró dentro de la Galería 1 de la cueva.

de carácter ritual, similares a los documentados en otros yacimientos (Liesau et al., 2013-2014: 66).

Los objetos depositados en Castillejo del Bonete son de características muy diversas (Benítez de Lugo Enrich et al., 2015b). Entre ellos cabe destacar una abundante colección de piezas de cobre en buen estado de conservación (Montero Ruiz et al., 2014). Se trata de útiles, no de adornos; este dato indica un uso antiguo de Castillejo del Bonete, dado que en fechas avanzadas de la Prehistoria reciente es cuando proliferan los adornos de bronce, y especialmente lo hacen en contextos funerarios. Aquí no se han encontrado. Puñales de remaches, punzones, cinceles y puntas de flecha (que son en todos los casos de tipo Palmela) forman parte de las casi tres decenas de objetos de cobre recuperados. Otro dato que avala el uso antiguo del monumento es que no se han documentado aquí piezas de bronce, sino sólo de cobre bastante arsenicado, en torno al 2,7\% (Benítez de Lugo et al., 2015b: 119).

Las cerámicas son, juntos a los restos óseos, la clase de materiales más abundante en Castillejo del Bonete. La cerámica recuperada aquí es similar a otras encontradas en yacimientos tradicionalmente considerados poblados, como es el caso de la motilla de El Azuer o la motilla de El Retamar. Algunos recipientes cerámicos fueron depositados dentro de tumbas cerradas, como es el caso del vaso carenado y de la olla globular que contenía metal, encontrados dentro de la tumba 4, en la que fueron enterrados dos individuos dentro del denominado Recinto 1 , cuya puerta fue clausurada con mampostería trabada con barro para evitar el acceso a su interior (véanse las piezas referidas musealizadas en fig. 10A y 10B; las piezas in situ, durante el proceso de excavación, en Benítez de Lugo et al., 2014b: 81, fig. 7A). FIG 10. Otras piezas han sido encontradas fragmentadas y rotas, dispersas por todo el complejo, pero también en ocasiones han aparecido colocadas en muros; incluso dentro de la cueva, como es el caso de un vaso alto de base cóncava, perfil recto, dos mamelones y labio decorado mediante ungulaciones (fig. 10C). El repertorio cerámico incluye no sólo recipientes, sino también materiales de la vida cotidiana como cucharas y queseras (fig. 10; Benítez de Lugo et al., 2007: 253; lam. 6). Las pesas, fusayolas y queseras encontradas en Castillejo del Bonete revelan una explotación de los productos secundarios (leche, lana, etc.) por parte de la comunidad que los produjo. Importante es señalar la presencia aquí de cerámicas con decoración incisa típicas del grupo Dornajos. Presentan las clásicas rebabas producidas al pasar el punzón sobre la pasta fresca al ejecutar su clásica decoración de carácter sinuoso, debido a que la decoración se realiza a pulso y con gran variedad de diseños; tanto al exterior del recipiente como, especialmente, al interior (fig. 11A; Garrido Pena, 1999) FIG 11. Esta característica diferencia estas cerámicas de las campaniformes del estilo Ciempozuelos. También se han recuperado decoraciones esquemáticas soliformes o rellenas de pasta blanca caliza (fig. 11B). Es importante señalar que esta clase de cerámicas con decoración incisa se han encontrado en todos los casos rotas en pequeños fragmentos, a diferencias de los recipientes lisos, varios de los cuales se han recuperado completos. Este hecho ha de ser analizado en el futuro con atención, pues podría estar poniendo de manifiesto una utilización diferencial 


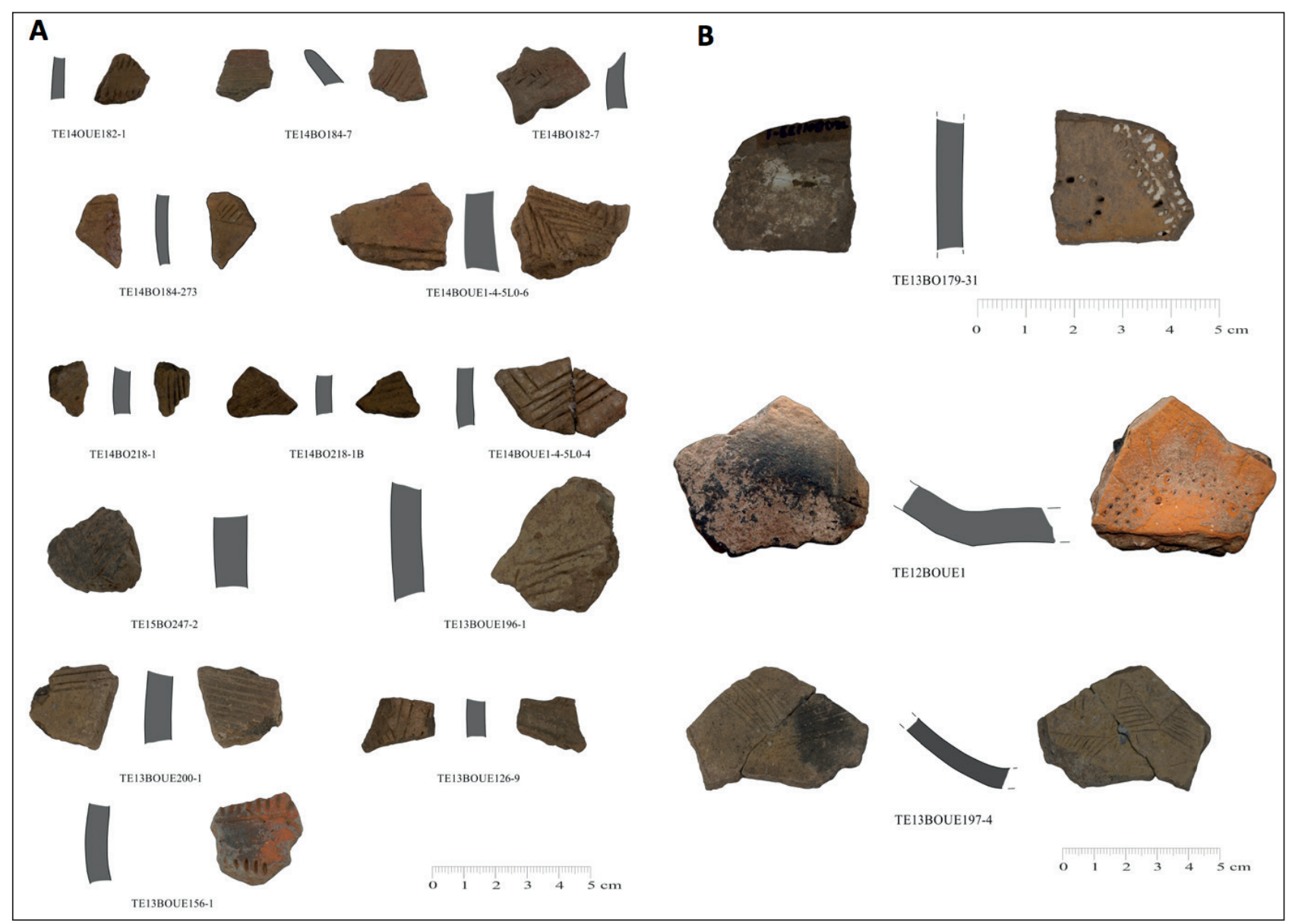

Figura 11. Castillejo del Bonete. Galbos con decoración incisa característica del Grupo Dornajos (A) o rellena de pasta blanca caliza y con decoración soliforme esquemática $(B)$.

entre ambas clases de productos. Aquellos que presentan decoración incisa pudieron haber sido rotos intencionalmente en el lugar tras ser usados. Otra posibilidad es que su manufactura, resistencia y conservación hayan sido mucho peores. La realización de análisis arqueométricos dirigidos a estudiar esta posibilidad será fundamental para verificar, o no, esta hipótesis.

También se encuentran en este yacimiento botones: tanto de marfil con perforación en $\mathrm{V}$ como de hueso sobre placa rectangular de sección plana con perforación central (Benítez de Lugo Enrich et al., 2015a).

Se han recuperado, además, numerosos adornos personales: un colgante elaborados con concha marina de la familia Collumbellidae (Benítez de Lugo Enrich et al., 2015b: 128), otro sobre gran colmillo inferior izquierdo de $78 \mathrm{~mm}$ de jabalí (fig. 12.10) y una colección con decenas de cuentas de madera fósil, variscita procedente de Palazuelo de las Cuevas (Aliste, Zamora) o hueso, tanto discoidales como tubulares (fig. 10.7), así como colgantes sobre incisivos de cérvido (fig. 12.8; Benítez de Lugo Enrich et al., 2015b: 125 y 127; Odriozola Lloret et al., 2016).

La industria ósea se ha elaborado mayoritariamente a partir de costillas metatarsos y metápodos de ovicápridos, aunque también fue utilizada materia prima procedente de bóvidos, suidos, cérvidos o liebres. Los punzones de hueso (al igual que los de cobre) son numerosos (muestra en figs. 12.1 a 12.5). Elaborados a partir de hueso se han documentado puntas de flecha tipo Palmela y otros útiles, así como un idoliforme sobre placa plana de hueso con dos pares de escotaduras encontrado al final de la Galería 2 de la cueva, en el acceso a la Galería 4.

Los huesos humanos se hallan en diferentes formatos: dentro de tumbas (esqueletos en conexión anatómica) -en ocasiones dobles, como es el caso de la Tumba 4 (Benítez de Lugo et al., 2014a: 167) o de la tumba 5 (Benítez de Lugo y Esteban, 2018)-, o bien en depósitos secundarios de huesos retirados del enterramiento original una vez descarnados para ser posteriormente recolocados, o incluso dispersos por todo el yacimiento, como es habitual en cualquier área cementerial de uso recurrente. Al igual que en el caso del Cerro Ortega, en Castillejo del Bonete se aprecia un programa ritual que produce el movimiento de los restos de los difuntos. Aunque el estudio antropológico se encuentra en este momento pendiente de conclusión, es posible avanzar que el número de individuos localizados es relativamente escaso (alrededor de una veintena) en relación con el largo período de tiempo en que este lugar fue utilizado. Parece que no todos los individuos de la comunidad fueron enterrados aquí, sino sólo algunos, aunque de ambos sexos y diferentes rangos 


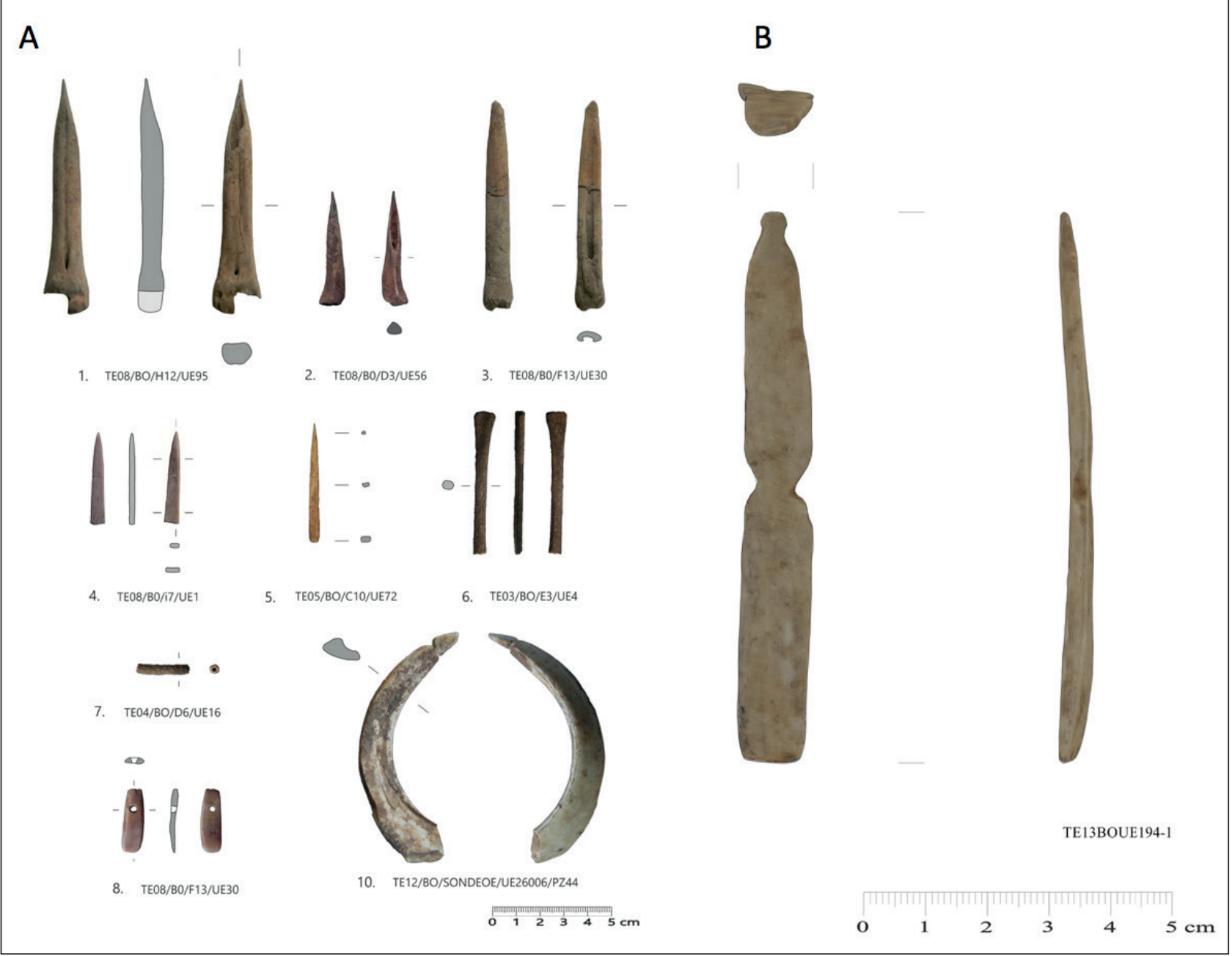

Figura 12. Castillejo del Bonete. Industria ósea. A: útiles y adornos personales. B: Ídolo.

de edad; quizás vinculados por algún tipo de parentesco -ficticio o real-como pudo suceder en la cueva sepulcral de El Rebolosillo (Torrelaguna, Madrid), utilizado entre 2620 y 2430 cal AC (Díaz del Río et al., 2017: 81). Cabe señalar que existe constancia de enterramientos en fosas y píthoi, no tumulares, en otros lugares de las proximidades de Castillejo del Bonete (Benítez de Lugo Enrich, 20142015: 199). Algunas personas enterradas en este lugar del interior peninsular se alimentaron con proteína marina (Salazar García et al., 2013). En el interior de la cueva sepulcral se han encontrado dos estelas de caliza, una de ellas con decoración natural a base de fósiles de bivalvos marinos del Secundario que no procede del entorno.

Sobre alguna de las tumbas, como es el caso de la número 4, se encendió una hoguera encima de la capa de tierra que cubría a los muertos. El calor del fuego alteró parte del contenido de la tumba, tostando algunos huesos una vez estaban descarnados (Benítez de Lugo et al., 2014a: 167; lam. 18). En esa hoguera se clavó o arrojó una flecha, cuya punta tipo Palmela se recogió con el pedúnculo doblado entre las cenizas (Montero Ruiz et al., 2014: 116; fig. 6.1). Al igual que sucede en Cueva Maturras y Camino de Yeseras, se vuelve a confirmar el uso del fuego en ámbitos rituales y funerarios de la Prehistoria reciente en la Meseta Sur. La utilización del fuego en esta clase de ámbito puede obedecer a diferentes causas, como son la purificación y limpieza, la destrucción ritual y clausura del lugar o el acompañamiento litúrgico durante el sepelio (Gutiérrez et al., 2002: 108; Ríos et al., 2012: 284).

Entre los restos de fauna recuperados en este yacimiento predominan mayoritariamente los de ovicápridos. Tanto éstos como los bóvidos fueron mantenidos con vida, sin ser sacrificados, hasta edad adulta. Este patrón indica también una voluntad de aprovechamiento de los productos derivados. Existen evidencias de que el sacrificio de los animales y su descuartizamiento pudieron realizarse en este entorno ritual. Así parece corroborarlo el hecho de que aparezcan representadas todas las partes anatómicas del esqueleto de estas especies. Sólo una pequeña minoría de los huesos animales presentan muestras de procesamiento calorífico.

Cazoletas excavadas en piedra de $8 \mathrm{~cm}$ de diámetro y 3 de profundo -similares a otras encontradas en diferentes lugares sin contexto arqueológico, que han venido resultando de difícil interpretación- aparecen junto a huesos humanos en el nivel de uso del Túmulo 2, cuya cámara pudo haberse cerrado mediante una falsa cúpula. Este 
túmulo tiene aproximadamente $9 \mathrm{~m}$ de diámetro y una altura de $1,5 \mathrm{~m}$ y estaba en uso a finales del III milenio y a comienzos del II cal AC.

Es importante insistir en que, aunque la cultura material es la propia de un poblado, no existen aquí cabañas. Con las evidencias disponibles es posible afirmar que este fue lugar de celebración (comida, bebida, depósito de objetos y acciones cuyo desarrollo empezamos a desvelar), muy visible desde la lejanía y, además, dotado de un enorme interés arqueoastronómico.

La orientación astronómica de las construcciones levantadas en Castillejo del Bonete permite calificar a este complejo como 'monumento solar'. Su construcción presenta un marcador del orto solar en el solsticio de invierno muy llamativo y preciso sobre el rasgo topográfico más conspicuo de todo el horizonte que rodea al yacimiento: la Peña del Cambrón. Varios corredores del monumento disponen de orientaciones con posible significado astronómico y/o topográfico. Resulta especialmente significativo que los corredores B y 1 (así como las galerías de la cueva que se extienden por debajo de estos corredores) se encuentran orientados hacia el orto y ocaso, respectivamente, del Sol en el solsticio de invierno; el mismo momento del año en que se produce el orto sobre El Cambrón. Otros corredores parecen presentar también orientaciones respecto a los ejes cardinales e incluso hacia el orto solar del solsticio de verano (Benítez de Lugo y Esteban, 2017; Esteban y Benítez de Lugo, 2016).

Los análisis palinológicos realizados en este yacimiento aportan información paleocológica de alcance, registrándose en este entorno a finales del III Milenio cal AC la descomposición del paisaje agrario calcolítico en favor de un entorno pastoril, dominante a comienzos de la Edad del Bronce. Es un proceso de transformación ambiental vinculable con el Evento Climático $4.2 \mathrm{ka} \mathrm{BP}$ (Benítez de Lugo y Mejías, 2016). Estos datos son similares a otros documentados en yacimientos de la Meseta. Una fase de extrema aridez se verifica entre c. 1950-1800 cal AC, pudiendo encontrarse esta contingencia climática en relación directa con la utilización de las motillas, en esta misma cultura del Bronce de La Mancha. El registro paleoambiental de Castillejo del Bonete ofrece pruebas sustanciales sobre la historia de la vegetación del entorno inmediato al yacimiento, desde un momento previo a la ocupación de la cueva en el que la antropización del medio es nula, a otro posterior en el que la cobertura arbórea va disminuyendo progresivamente y la presión del pastoreo se manifiesta. Todo ello en un marco paleoclimático típico de la transición Calcolítico-Bronce que, en el caso de nuestra área de estudio, se manifiesta por un periodo excepcionalmente árido entre 2200-1800 cal. AC, que se continúa con otro de incremento progresivo de la pluviosidad en los tres siglos posteriores (Benítez de Lugo et al., 2015b; López Sáez et al., 2009, 2014a y 2014b).

Castillejo del Bonete estuvo en uso, al menos, desde finales del IV milenio cal AC hasta mediados del II milenio cal AC (Benítez de Lugo et al., 2018). Este dato pone de manifiesto que la diferencia Calcolítico-Bronce inicial es, al sur de la Meseta, más académica que real. También que, entre el III y II milenios cal AC, no se aprecia fractura cultural, y sí continuidad constatable mediante la utilización de complejos tumulares monumentales. Este yacimiento forma parte de la eclosión de manifestaciones funerarias experimentadas a partir del Calcolítico, sin que la fecha canónica de inicio de la Edad del Bronce, en torno a 2200 cal AC, se aprecie decaimiento en el uso de este gran monumento ceremonial.

\section{DiscuSión y CONCLUSIONES}

Una revisión de los estudios sobre Prehistoria reciente en el sur de la Meseta permite detectar una abrumadora descompensación entre las excavaciones, prospecciones, tesis doctorales, tesinas y publicaciones dedicadas al Bronce de La Mancha, frente a los inexistentes proyectos de investigación destinados a estudiar el Neolítico y el Calcolítico en este territorio. Así las cosas, no es extraño que el Alto Guadiana haya sido calificado, de forma poco acertada, como un 'desierto neolítico' con bajísima densidad demográfica, que no pudo sino dar lugar a grupos marginales, fundamentalmente pastores. Algo parecido sucedía hasta hace poco con el Calcolítico, que ahora se está empezando a conocer y revela relaciones entre esta zona con las cuencas bajas de los ríos Guadiana y Guadalquivir, así como con la cuenca media del Tajo. La vieja idea de negar la más mínima complejidad social a los grupos neolíticos y calcolíticos del interior meseteños ya ha sido superada en otras cuencas como la del Tajo (Bueno et al., 2005: 69; Garrido, 2000: 26; Liesau et al., 2013-2014; Díaz del Río et al., 2017; Arteaga et al., 2017), pero no hasta ahora en la del Alto Guadiana.

En el ámbito del ritual funerario, las evidencias disponibles revelan que en el tránsito del VI al V milenio cal AC, durante el Neolítico inicial, se están practicando en este territorio inhumaciones individuales cerca de los poblados, en posición fetal y dentro de fosas con forma de útero materno que han sido cuidadosamente preparadas, en cuyo interior se introducen además algunos objetos utilizados en la vida ordinaria. La información de este primer enterramiento conocido al sur de la Meseta procede de la tumba de Villamayor de Calatrava (Rojas y Villas, 2000).

Los siguientes datos disponibles corresponden a más de un milenio después. En este caso la información procede ya de dos lugares: Cueva Maturras y Cerro Ortega. Es interesante comprobar como en el Neolítico final, a través de estos dos yacimientos se han atestiguado diferentes clases de ritos funerarios, en ambos casos ya colectivos, dentro de abrigos rocosos y con ajuares asociados. En el primer caso los difuntos se colocaron dentro de una construcción de madera levantada dentro de la cavidad, encendiéndose un potente fuego antes de sepultar el conjunto con tierra y grandes bloques de piedra. Se trata de un enterramiento primario. En el segundo caso, los huesos de al menos 19 difuntos recuperados no se encontraron en conexión anatómica, lo que puede estar revelando que se 
trata de un sepulcro secundario, ubicado también dentro de un abrigo natural que colapsó por circunstancias naturales. Aunque es preciso recordar que este abrigo sufrió un hundimiento por causas naturales y fue afectado por una escorrentía, lo que a buen seguro supuso un movimiento postdeposicional de los estratos arqueológicos, la existencia de paralelos como los 21 individuos (NMI) depositados de forma secundaria en El Rebolosillo permiten sostener la existencia de esta clase de ritual funerario -utilización de abrigos para depósitos primarios y secundarios- en la Meseta sur a finales del IV milenio cal AC.

En Huerta Plaza, durante el Calcolítico final, un difunto fue enterrado dentro de una estructura siliforme próxima al poblado, junto a otras que fueron amortizadas como basureros (Rojas y Gómez Laguna, 2000).

No obstante, el principal referente para reconstruir el ritual funerario durante el Calcolítico es Castillejo del Bonete, monumento solar orientado astronómicamente que aúna, por vez primera, representaciones pictóricas esquemáticas con construcciones y enterramientos bien datados. El uso de este centro ceremonial para celebrar reuniones rituales, con los ancestros como argumento, se prolongó durante un milenio y medio, incluyendo su desarrollo el período en el que permaneció activa la Cultura de las Motillas. Su ocaso probablemente fue parejo a la ruina de los linajes sobre los que se construyó la Prehistoria reciente en La Mancha. La manipulación de los ancestros fue una constante a lo largo de este tiempo, de forma similar a lo documentado en otros yacimientos de la Meseta (Liesau et $a l .$, 2014). Es interesante señalar que el ocaso de la Cultura de las Motillas parece coincidir con el final del uso de Castillejo del Bonete. Este hecho revela una continuidad de los referentes metafísicos de las comunidades calcolíticas hasta el Bronce medio, que se rompe al llegar el Bronce final. En Castillejo del Bonete la reutilización del espacio funerario durante quince siglos supuso la sucesiva alteración de enterramientos anteriores, que no son todos los de la comunidad. Sólo alrededor de una veintena de muertos enterrados aquí a lo largo de casi mil años significa que la mayor parte de la gente no se enterraba en este monumento. Cerca de este complejo tumular hay constancia tanto de poblados en altura como de otra clase de lugares funerarios, con enterramientos en pithoi y fosas (Benítez de Lugo et al., 2014-2015). Este lugar central ceremonial revela por vez primera un interés de las primeras sociedades complejas al sur de La Mancha en monumentalizar el paisaje a partir de arquitecturas claramente visibles desde la lejanía, creando centros ceremoniales dentro de los cuales fueron depositados muertos, incluyendo algunos procedentes de lugares lejanos. Estos monumentos fueron construidos con mampostería irregular, en general sin grandes ortostatos, pero con las cámaras, túmulos y corredores clásicos en el lenguaje de la cultura megalítica. Bocapucheros (Almagro) utiliza este mismo tipo de mensaje (Benítez de Lugo, 2015: 69). La gestión de estas prácticas rituales sobre los difuntos debió contar con un grupo de 'especialistas' en prácticas religiosas' (García San Juan et al., 2017), que pudieron practicar ritos de comensalidad al servicio de una incipien- te jerarquización social y del control de recursos básicos, como el agua y el territorio. Las costumbres mortuorias aquí detectadas sugieren la manipulación de los cadáveres en diversos momentos de su proceso de esqueletización; una práctica atestiguada en el interior peninsular en el III milenio cal AC (Liesau et al., 2014; Flores y Garrido, 2014; Díaz del Río, 1986; Díaz del Río et al., 2017). La orientación astronómica de esta clase de edificios señala un interés en marcar las estaciones anuales. La relación de estas arquitecturas con los ciclos de muerte-resurrección de los astros parece haber inspirado relatos acerca de la vida y la muerte de estas primeras sociedades complejas, en las que destacan la estirpe y las referencias a la tradición para justificar el estatus (Bueno et al., 2005: 69). Las decoraciones soliformes esquemáticas detectadas en varias cerámicas pueden estar señalando la existencia de recipientes vinculados a esos programas rituales.

Otros enclaves de este territorio pueden ayudar a reconstruir las prácticas religiosas de estas primeras sociedades metalúrgicas.

La Encantada (Granátula de Calatrava, Ciudad Real) situada también en un emplazamiento de alta visibilidadha sido definida por sus investigadores, al menos durante sus últimas fases, como una 'ciudad de los muertos', en la que se prodigan las construcciones de carácter religioso. Éstas son 'verdaderos templos, en algunos casos funerarios. (...) Se trata de espacios de carácter claramente ritual, debido precisamente a su relación con las sepulturas; las cuáles, en algunos casos, han sido construidas simultáneamente al edificio' (Sánchez Meseguer y Galán Saulnier, 2004: 116,130 y 132). Es interesante llamar la atención sobre las características de los 'silos' encontrados en este 'poblado'. Es el caso de los 'silos anidados' (Sánchez Meseguer y Galán Saulnier, 2004: 128 y 129, lam. 11), construidos inexplicadamente fuera del perímetro protegido del 'castellón'. Además de esta clase de silos aparecen otros, también aislados. 'Varios de estos silos fueron amortizados como lugares para enterrar (...) y en el interior de varios de ellos se hallaron grandes recipientes cerámicos, tanto completos e incompletos' (Sánchez Meseguer y Galán Saulnier, 2004). Todo ello fue cubierto con tierra y piedras. 'Silos' que no son silos, sino depósitos al servicio de un programa ritual funerario, y recintos relacionados con sepulturas es lo que hemos descrito en Castillejo del Bonete.

En Los Dornajos (La Hinojosa, Cuenca) se han excavado casi $300 \mathrm{~m}^{2}$ de un tell; un 'cerro de tipo artificial' en el cual no hay evidencias de hábitat; ni en la propia 'morra' ni en su entorno inmediato se han encontrado hogares, basureros, almacenes, etc. (Galán Saulnier, 2016: 18, 37, 46 y 84). Es decir, se trata de un túmulo. Las excavaciones arqueológicas realizadas allí "han complicado la interpretación del yacimiento, más que aclararla" (Galán Saulnier y Fernández Vega, 1982: 48). De entre los datos publicados acerca de este yacimiento llama la atención, entre otros, la mención a la existencia de numerosos 'silos' empotrados en el cuerpo del túmulo. La mayoría de ellos se han encontrado vacíos, si bien en alguno de ellos -como es el caso del 'Hoyo 5'- se depositaron 
vasos cerámicos de diferentes tamaños. En el túmulo se han encontrado fragmentos de casi un millar de recipientes cerámicos, además de industria ósea, armas y adornos personales. Cabe señalar que estos 'silos' u 'hoyos' en ocasiones tienen tan sólo 20 ó $30 \mathrm{~cm}$ (Galán Saulnier, 2016: 79 y 86), resultando completamente inoperativos como silos. Dentro del túmulo se encontró "un gran muro, cuya función no es tan obvia, como tampoco lo es la del supuesto silo de mampostería". En el entorno inmediato de Los Dornajos se encuentra un conjunto de grabados rupestres esquemáticos en el cerro de San Bernardino. También existen cazoletas excavadas en roca, similares a otras encontradas al sur de Ciudad Real (Fernández Rodríguez y López Fernández, 2015) y por toda la Meseta, generalmente descontextualizadas y de difícil interpretación. Las prospecciones arqueológicas realizadas en torno a Los Dornajos permitieron detectar 'la ocupación de buena parte del territorio del actual municipio de La Hinojosa por gentes de distintos momentos de la Edad del Bronce' (Galán Saulnier, 2016: 33). Ninguno de esos asentamientos parece haber estado monumentalizado. En síntesis, nuevamente estamos ante un yacimiento en el que hay 'silos' que no son silos, un túmulo que fue interpretado como un tell resultante de la ruina de un poblado, con muros en su interior que no corresponden con cabañas, asociado a cazoletas y arte esquemático como los que se han encontrado bajo los túmulos de Castillejo del Bonete y que, como este yacimiento, podría ser un lugar ceremonial central. La información disponible permite plantear la posibilidad de que en el entorno de Los Dornajos y el cerro de San Bernardino esté presente el lenguaje simbólico fosilizado en otros centros ceremoniales de la Prehistoria reciente en La Mancha.

Lo mismo sucede en el caso del pozo monumentalizado de la motilla del Azuer; otra estructura con apariencia tumular muy visible desde la lejanía en la Llanura Manchega, con más de un centenar de muertos enterrados en su interior; los varones sobre su costado izquierdo y las mujeres y niños sobre el derecho (Nájera et al., 2012: 162). De forma similar a lo detectado en Castillejo del Bonete, se han conservado estelas sobre algunas tumbas (Nájera et al., 2012: 159, lam. IVb). Se ha indicado que 'la distribución de la necrópolis coincide con el área espacial del poblado, documentándose incluso bajo el piso de las propias viviendas' (Torres Mas, 2015: 21). Lo cierto es que las tumbas aparecen en el interior de la motilla, pero 'al exterior de la fortificación se sitúan las viviendas del poblado' (Nájera et al., 2012). Por otra parte, ni una cabaña ha sido descrita en la motilla del Azuer, ni al interior ni al exterior del poblado. Las estructuras arrasadas documentadas al exterior de la motilla perfectamente pueden corresponder al desarrollo de actividades económicas relacionadas con la explotación hidráulica del pozo. A pesar de las dudas que suscita la interpretación de la motilla como poblado en llano, resulta claro que fue también un lugar central de alto valor simbólico y estratégico. En torno a las motillas se distribuyeron poblados en llano como Las Saladillas (Alcázar de San Juan), en altura como la Mesa del Almendral y campos de silos como La Villeta (Ciudad Real), ninguno de los cuales fueron monumentalizados.

No estamos planteando que Castillejo del Bonete, La Encantada, Los Dornajos y la motilla de El Azuer sean el mismo tipo de edificación. Sí hemos puesto de manifiesto que en estos lugares han quedado plasmadas las evidencias de prácticas rituales, siempre evanescentes y difíciles de detectar.

Un valor del trabajo desarrollado en el recinto ceremonial de Castillejo del Bonete ha sido el de revelar que manifestaciones culturales documentadas en otros yacimientos pueden tener que ver con aspectos simbólicos.

Los estudios en Cerro Ortega y Castillejo del Bonete permiten constatar que a esta zona llegaron personas y materiales procedentes de lugares lejanos, tales como como botones de marfil y cuentas de ámbar o variscita.

En el sur de La Mancha se elaboraban adornos personales en forma de colgantes ovales sobre concha marina importada (Benítez de Lugo et al., 2003-2004), además de los objetos habituales en estas primeras sociedades productoras. Materiales volcánicos (basalto y obsidiana, principalmente) o piezas líticas elaboradas con ellos también fueron distribuidos por este territorio (Campo de Calatrava es zona volcánica).

En Sierra Morena (Almadén y su entorno) se encuentran las minas de cinabrio más ricas y antiguas del mundo, cuya explotación fue centralizada a partir de la Protohistoria a través de Sisapo (La Bienvenida-Almodóvar del Campo). El cinabrio puede presentar en superficie tonalidades brillantes, de rojizas a plateadas (si se trata de mercurio nativo), y desde tiempos inmemoriales se ha utilizado para conservar huesos humanos y pinturas rupestres. El enterramiento individual A-36 E03-III de Camino de Yeseras, inhumado con diadema de oro, 22 cuentas y tres botones de marfil de perforación en $\mathrm{V}$, fue cubierto por un pigmento rojo cuyo análisis mediante microscopio electrónico de barrido permitió determinar que el mineral cubriente usado era cinabrio o bermellón, altamente tóxico, única fuente de mercurio, que no se encuentra en la cuenca del Tajo (Ríos et al., 2012: 289). Por otra parte, en las cuevas funerarias artificiales del Valle de las Higueras (Huecas, Toledo) se ha podido documentar que el cinabrio formó parte del ritual neolítico, con un protagonismo notorio; en concreto en las cuevas 1, 3 y, especialmente, en la 5. Una hipótesis a verificar en el futuro será que el cinabrio utilizado la cuenca media del Tajo fuera obtenido en la zona del sur de la Meseta ahora sometida a estudio. Aquí se encuentran las reservas de cinabrio más importantes del mundo, cuya explotación ya mencionan Estrabón, Vitrubio y Plinio. Parece verificarse una de las primeras manifestaciones de esta clase de explotación mineral, dentro del incremento de los intercambios de productos, cuya intensificación se aprecia a lo largo del III milenio cal AC (Bueno et al., 2005: 81). El cinabrio y materiales volcánicos como la obsidiana fueran recursos minerales locales gestionados desde las comunidades asentadas al sur de la Meseta.

Existen bases para afirmar que por la cuenca del Alto Guadiana y la Llanura Manchega durante la Prehistoria 
reciente circularon gentes, ideas y productos de diferente clase; dirigidos hacia y procedentes de lugares lejanos. Los poblados se articularon en torno a construcciones monumentales tumulares dotadas de una fuerte carga simbólica, que funcionaron como lugares centrales de la comunidad. Para controlar el agua y el territorio se utilizaron argumentos como los ancestros, el culto solar y esas arquitecturas que por vez primera monumentalizaron el paisaje.

Castillejo del Bonete es un centro ceremonial monumentalizado muy visible desde la lejanía, pero los poblados que tiene a su alrededor no lo son. El programa de monumentalización de las sociedades calcolíticas del sur de la Meseta afectaba a centros ceremoniales con presencia de difuntos, pero no a los poblados distribuidos en torno a ese lugar central. Esta pauta, conocida en otros lugares del Mediterráneo, se aprecia también la motilla más estudiada.

Aunque aún faltan datos para poder explicar en toda su dimensión las épocas neolítica y calcolítica en la provincia de Ciudad Real, existen ya sobradas evidencias para desterrar la antigua idea de que en estos momentos el sur de la Meseta fue una zona deshabitada o retardataria, al margen de las influencias de otras zonas peninsulares más conocidas.

Castillejo del Bonete y Cerro ortega permiten constatar que no todos los lugares en donde aparecen objetos de la vida cotidiana son poblados. Materiales de la vida cotidiana habituales en los poblados se encuentran no sólo en lugares de hábitat, sino también en espacios que no son habitacionales: ceremoniales o funerarios. Por el hecho de que dentro de las motillas aparezcan silos y objetos usados en la vida cotidiana no debe necesariamente inferirse que se trate de poblados. También dentro de estructuras tumulares que no son poblados, como son Castillejo del Bonete o Los Dornajos, aparecen estructuras siliformes, cerámicas y otros objetos de uso cotidiano.

Las cerámicas del tipo Dornajos son un estilo regional propio de La Mancha, que en ocasiones puede pervivir con el estilo campaniforme Ciempozuelos. En las cerámicas del tipo Dornajos no se aprecian muchas de las convenciones relativas a sus aspectos más profundos de las campaniformes, como puedan ser las estructuras de ordenación de los motivos o la rica variedad de los soportes formales. Algunos autores proponen un posible origen del tipo cerámico Dornajos al final del horizonte Ciempozuelos (a comienzos del II milenio cal AC), verificándose su existencia hasta el Bronce pleno, durante la vigencia -y en íntima relación con el origen- de la Cultura de las Motillas. El grupo de las cerámicas del tipo Dornajos dentro del cual puede existir una diferencia estilística temporal aún pendiente de definición- podría, según algunos especialistas, ser heredero de las campaniformes no sólo estilísticamente, sino también en el plano social y ritual (Garrido Pena, 1999: 197, 229 y 237).

Sea como fuere, el fenómeno de la cerámica del tipo Dornajos se encuentra pendiente de investigación. La posible existencia de algún fragmento de esta clase entre el ajuar funerario del Cerro Ortega puede, quizás, retrotraer la fecha de origen propuesta hasta ahora para esta clase de cerámicas (o bien prolongar la vida útil del uso mortuorio de ese abrigo, lo que no se aprecia en ninguna de las dataciones absolutas realizadas hasta la fecha). A buen seguro las nuevas técnicas arqueométricas podrán aportar interesante información en este punto. La documentación de cerámicas del tipo Dornajos encontradas en contextos simbólicos y funerarios relacionados con la Cultura de las Motillas, como es el caso de Castillejo del Bonete, puede ayudar a entender el significado tanto de este grupo de cerámicas como de yacimientos cuya interpretación se encuentra en revisión.

\section{Agradecimientos}

La Junta de Comunidades de Castilla-La Mancha y el Ayuntamiento de Terrinches financian la investigación en Castillejo del Bonete. El Ayuntamiento de Villanueva de la Fuente autorizó el estudio del material arqueológico de Cerro Ortega depositado en su sala museográfica. El Museo de Ciudad Real y el Servicio de Conservación, Restauración y Estudios Científicos del Patrimonio Arqueológico de la Universidad Autónoma de Madrid han colaborado con esta investigación. Honorio Javier Álvarez García y Norberto Palomares Zumajo (arqueólogos) y María Benito Sánchez, Alexandra Muñoz García e Isabel Beltrán Gil (antropólogas) han codirigido en diferentes momentos las investigaciones en Castillejo del Bonete; Carlos Barrio Aldea y Bienvenido Maquedano Carrasco han dirigido la intervención en Cerro Ortega; sin todos ellos este trabajo no habría sido posible. Jaime Moraleda Sierra ha dibujado la figura 1. Gabriel Menchén Herreros ha dibujado las figuras 3-5 y 9-12. José Luis Fuentes Sánchez ha dibujado la figura 8 . La figura 6B fue realizada por Audio\&Visual Factory.

\section{Bibliografía}

Arteaga, C.; Liesau, C.; García, R.; Pérez, E.; Menduiña, R.; Vega, J. y Blasco, C. (2017): "The Ditched Enclosure of Camino de las Yeseras (Madrid): A Sedimentological Approach to the Study of some Singular Structures". Espacio, Tiempo y Forma (Serie I), 10: 77-94.

Barrio Aldea, C. y Maquedano Carrasco, B. (2000): “La necrópolis calcolítica de Cerro Ortega (Villanueva de la Fuente)". En L. Benítez de Lugo Enrich (coord.): El Patrimonio arqueológico de Ciudad Real. Métodos de trabajo y actuaciones recientes. Universidad Nacional de Educación a Distancia. Valdepeñas (Ciudad Real): 67-86

Benítez de Lugo Enrich, L.; Álvarez García, H.J.; Garrido Martínez, Mª.A.; Hermana Mendioroz, F.; Molina Cañadas, M. y Moraleda Sierra, J. (2003-2004): “El Calcolítico en el Alto Guadiana: artesanos de cuentas de collar en el interior peninsular: Los Parrales (Arenas de San Juan, Ciudad Real)". Espacio, tiempo y forma. Serie I (Prehistoria), 16-17: 189-211. 
Benítez de Lugo Enrich, L.; Álvarez García, H.J.; Moraleda Sierra, J. y Molina Cañadas, M. (2007): "Consideraciones acerca del Bronce de La Mancha a partir de la investigación de la cueva prehistórica fortificada de Castillejo del Bonete (Terrinches, Ciudad Real). Campañas 2003-2005”. En J.M. Millán y C. Rodríguez Ruza (coords.): Actas de las I Jornadas de Arqueología de Castilla-La Mancha (Cuenca, 2005). Universidad de Castilla-La Mancha. Cuenca: 231-262

Benítez de Lugo Enrich, L.; Álvarez García, H.J.; Fernández Martín, S.; Mata Trujillo, E.; Moraleda Sierra, J.; Morgado Rodríguez, A.; Palomares Zumajo, N.; Odriozola Lloret, C.; Morgado García, A. y Salazar-García, D.C. (2014a): "Castillejo del Bonete (Terrinches, Ciudad Real): complejo tumular prehistórico de la Cultura de las Motillas en el Alto Guadalquivir". Menga, Revista de Prehistoria de Andalucía, 5: 151-174.

Benítez de Lugo Enrich, L.; Mejías Moreno, M.; López Gutiérrez, J.; Álvarez García, H.J.; Palomares Zumajo, N.; Mata Trujillo, E.; Moraleda Sierra, J.; Menchén Herreros, G.; Fernández Martín, S.; Salazar-García, D.C.; Odriozola Lloret, C.; Benito Sánchez, M. y López Sáez, J.A. (2014b): “Aportaciones hidrogeológicas al estudio arqueológico de los orígenes del Bronce de La Mancha: la cueva monumentalizada de Castillejo del Bonete (Terrinches, Ciudad Real-España)". Trabajos de Prehistoria, 71 (1): 76-94. DOI: https:// doi.org/10.3989/tp.2014.12125

Benítez de Lugo Enrich, L.; Álvarez García, H.J.; Palomares Zumajo, N.; Mata Trujillo, E. y Moraleda Sierra, J. (2014-2015): “Investigación y gestión de un complejo monumental prehistórico en el borde meridional de la Meseta: Castillejo del Bonete (Terrinches, Ciudad Real). Quince años de intervenciones arqueológicas (2003-2015)". Arse, 48-49: 173-218.

Benítez de Lugo Enrich, L. (2015): "Los principales yacimientos de la Prehistoria Reciente en La mancha”. En M. Mejías, L. Benítez de Lugo, J.A. López Sáez y C. Esteban (eds.): Arqueología, hidrogeología y medio ambiente en la Edad del Bronce de La Mancha: la Cultura de las Motillas. Instituto Geológico y Minero de España. Madrid: 63-82.

Benítez de Lugo Enrich, L. y Mejías Moreno, M. (2015): "La prehistórica Cultura de las Motillas: nuevas propuestas para un antiguo problema". Veleia, 32: 111124. DOI: https://doi.org/10.1387/veleia.14981

Benítez de Lugo Enrich, L.; Schuhmacher, T.X.; Palomares Zumajo, N.; Álvarez García, H.J.; Mata Trujillo, E.; Moraleda Sierra, J.; Menchén Herreros, G. y Salazar-García, D.C. (2015a): "Marfil para los muertos en la Cultura de las Motillas: los botones de Castillejo del Bonete (Terrinches, Ciudad Real)". Madrider Mitteilungen, 56: 40-61.

Benítez de Lugo Enrich, L.; Palomares Zumajo, N.; Álvarez García, H.J.; Barroso Bermejo, R.; Benito Sánchez, M.; Hugues-Alexandra Blain; Bueno Ramírez, P.; De Balbín Behrmann; Fernández Martín, S., LópezSáez, J.A., Galindo Pellicena, M.A.; Garrido Martínez, M.A.; Laplana Conesa, C.; Mata Trujillo, E., Menchén Herreros, G., Montero Ruiz, I., Moraleda Sie- rra, J., Morgado Rodríguez, A., Odriozola Lloret, C.; Polo Martín, E.; Ruiz-Alonso, M., Sevilla García, P., Schuhmacher, T.X. y Salazar-García, D.C. (2015b): "Paleoecología y cultura material en el complejo tumular prehistórico de Castillejo del Bonete (Terrinches, Ciudad Real)". Menga, Revista de Prehistoria de Andalucía, 6: 112-140.

Benítez de Lugo Enrich, L. y Mejías Moreno, M. (2016a): "Aspectos hidrogeológicos, paleoambientales, astronómicos y simbólicos del Bronce de La Mancha". Arpi, 4: 345-356.

Benítez de Lugo Enrich, L. y Mejías Moreno, M. (2016b): "Hidrogeología y captación de aguas subterráneas en La Mancha durante la Prehistoria Reciente: la gestión de los recursos hídricos en la Cultura de las Motillas". Archivo de Prehistoria Levantina, 31: 137-168.

Benítez de Lugo Enrich, L. y Mejías Moreno, M. (2017): "The hydrogeological and paleoclimatic factors in Bronze Age Motillas Culture of La Mancha: the first hydraulic culture in Europe". Hydrogeology Journal, 25 (7): 1931-1950. DOI: https://doi.org/10.1007/ s10040-017-1607-z

Benítez de Lugo Enrich, L. y Esteban, C. (2018, en prensa): "Arquitecturas simbólicas orientadas astronómicamente durante el Calcolítico y la Edad del Bronce en el sur de la Meseta". SPAL, 27 (2).

Benítez de Lugo Enrich, L.; Álvarez García, H.J.; Barrio Aldea, C.; Benito Sánchez, M.; Fuentes Sánchez, J.L.; Márquez Mora, B.; Menchén Herreros, G.; Moraleda Sierra, J.; Odriozola Lloret, C.; Palomares Zumajo, N. y Salazar-García, D.C. (en prensa): "El sustrato cultural del Bronce de La Mancha: Neolítico y Calcolítico en el Alto Guadiana"

Bueno Ramírez, P.; Barroso Bermejo, R. y De Balbín Behrmann, R. (2005): "Ritual campaniforme, ritual colectivo: la necrópolis de cuevas artificiales del Valle de las Higueras, Huecas, Toledo". Trabajos de Prehistoria, 62 (2): 67-90. DOI: https://doi.org/10.3989/ tp.2005.v62.i2.69

Díaz del Río, P. (1986): “El enterramiento colectivo de 'El Rebolosillo’ (Torrelaguna)”. Reunión de Arqueología Madrileña. Madrid: 198-200.

Díaz del Río, P.; Consuegra, S.; Audije, J.; Zapata, S.; Cambra, O.; González, A.; Waterman, A.; Thomas, J.; Peate, D.; Odriozola, C.; Villalobos, R.; Bueno, P. y Tykot, R. (1986): "Un enterramiento del III milenio AC en el centro de la Península Ibérica: El Rebolosillo (Torrrelaguna, Madrid)". Trabajos de Prehistoria, 74 (1): 68-85. DOI: https://doi.org/10.3989/tp.2017.12184

Esteban, C. y Benítez de Lugo Enrich, L. (2016): "Archaeoastronomy in Bronze Age sites of La Mancha (Spain)". Mediterranean Archaeology and Archaeometry, 16 (4): 283-289. DOI: https://doi.org/10.5281/ zenodo. 220948

Fernández Martín, S.; Benítez de Lugo Enrich, L. y Palomares Zumajo, N. (2015): "La cerámica del yacimiento arqueológico Castillejo del Bonete (Terrinches, Ciudad Real). Estudio morfológico y tecnológico". Complutum, 26 (1): 133-152. DOI: http://dx.doi.org/10.5209/ rev_CMPL.2015.v26.n1.49344 
Fernández Rodríguez, M. y López Fernández, M. (2015): "Las cazoletas del polígono de La Nava (Puertollano). Estudio preliminar". I Congreso nacional de Ciudad Real y su provincia, t. I. Instituto de Estudios Manchegos. Ciudad Real: 57-71.

Flores, R. y Garrido, R. (2014): “Campaniforme y conflicto social: evidencias del yacimiento de Humanejos (Parla, Madrid)". Actas de las IXjornadas de Patrimonio Arqueológico en la Comunidad de Madrid (Madrid, 2012). Madrid: 159-167.

Galán Saulnier, C. y Fernández Vega, A. (1982): “Excavaciones en Los Dornajos (La Hinojosa, Cuenca). Campañas de 1981 y 1982". Cuadernos de Prehistoria y Arqueología de la Universidad Autónoma de Madrid, 10: 31-48.

Galán Saulnier, C. (2016): El yacimiento arqueológico de Los Dornajos (La Hinojosa, Cuenca). Arkatros. Madrid.

García Sanjuán, L.; Scarre, C. y Wheatley, D.W. (2017): "The Mega-Site of Valencina de la Concepción (Seville, Spain): Debating Settlement Form, Monumentality and Aggregation in Southern Iberian Copper Age Societies". Journal of World Prehistory, 20 (3): 239257. DOI: https://doi.org/10.1007/s10963-017-9107-6

Garrido Pena, R. (2000): El campaniforme en la Meseta Central de la Península Ibérica (c. 2500-2000 AC). BAR International Series 892. Oxford.

Gil Pitarch, P.; Miquel Feucht, M.J.; Negre Muñoz, Ma.C.; Polo Cerdá, M. y Villalaín Blanco, J.D. (1999): "Estudio antropológico y paleopatológico de los restos óseos del yacimiento neolítico de Villanueva de la Fuente (Ciudad Real)". II Congrés del Neolític a la Península Iberica. Saguntum-PLAV, Extra 2: 387-391.

Liesau, C.; Vega, J.; Daza, A.; Ríos, P.; Menduiña, R. y Blasco, C. (2013-2014): "Manifestaciones simbólicas en el acceso noreste del Recinto 4 de foso en Camino de Yeseras (San Fernando de Henares, Madrid)". Saldvie, 13-14: 53-69.

Liesau, C.; Ríos, P.; Vega, J.; Menduiña, R. y Blasco, C. (2014): "Buscando a los ancestros: la manipulación de los restos de las tumbas campaniformes en Camino de Yeseras". Actas de las IX Jornadas de Patrimonio Arqueológico de la Comunidad de Madrid (noviembre de 2012). Comunidad de Madrid. Madrid: 137-148.

Montero Ruiz, I.; Benítez de Lugo Enrich, L.; Álvarez García, H.J.; Gutiérrez-Neira, P.C.; Murillo-Barroso, M.; Palomares Zumajo, N.; Menchén Herreros, G.; Moraleda Sierra, J. y Salazar-García, D.C. (2014): "Cobre para los muertos. Estudio arqueométrico del material metálico procedente del monumento megalítico prehistórico Castillejo del Bonete (Terrinches, Ciudad Real-España)". Zephyrus, 73: 109-132.DOI: https://doi.org/10.14201/zephyrus201473109132

Nájera, T.; Jiménez Brobeil, S.; Molina, F.R.; Delgado, A. y Laffranchi, Z. (2012): "La aplicación de los métodos de la Antropología Física a un yacimiento arqueológico: la motilla del Azuer". Cuadernos de Prehistoria de la Universidad de Granado, 22: 149-183.
Odriozola, C.; Benítez de Lugo Enrich, L.; Villalobos, R.; Martínez-Blanes, J.M.; Avilés, M.; Palomares, N.; Benito, M.; Menchén, G.; Barrio, C. y Salazar-García, D.C. (2016): "Personal body ornamentation on the Southern Iberian Meseta: An archaeomineralogical study". Journal of Archaeological Sciences: Reports, 5: 156167. DOI: https://doi.org/10.1016/j.jasrep.2015.11.021

Polo Cerdá, M.; Negre Muñoz, Mª.C.; Miquel Feucht, M.J.; Gil Pitarch, P. y Villalaín Blanco, J.D. (1999): "Estudio paleodontológico y paleonutricional de los restos óseos del yacimiento neolítico de Villanueva de la Fuente (Ciudad Real)". Il Congrés del Neolític a la Península Iberica. Saguntum-PLAV, Extra, 2: 379-385.

Polo Martín, E.; Bueno Ramírez, P.; De Balbín Behrmann, R.; Benítez de Lugo Enrich, L. y Palomares Zumajo, N. (2015): "Manifestaciones gráficas en la Cueva-Sima del Castillejo del Bonete (Terrinches, Ciudad Real)". Arpi, 2: 90-107.

Ríos, P.; Liesau, C.; Aliaga, R. y Vega, J. (2012): "Estudio interdisciplinar de dos enterramientos calcolíticos procedentes del yacimiento de Camino de Yeseras (San Fernando de Henares, Madrid)". Actas de las VI Jornadas de Patrimonio Arqueológico de la Comunidad de Madrid (diciembre de 2009). Comunidad de Madrid. Madrid: 279-294.

Rojas Rodríguez-Malo, J.M. y Gómez Laguna, A. (2000): "Intervención arqueológica en el yacimiento de Huerta Plaza (Poblete) y su relación con otros yacimientos calcolíticos de la provincia de Ciudad Real”. En L. Benítez de Lugo Enrich (coord.): El Patrimonio arqueológico de Ciudad Real. Métodos de trabajo y actuaciones recientes. Universidad Nacional de Educación a Distancia. Valdepeñas (Ciudad Real): 21-42.

Rojas Rodríguez-Malo, J.M. y Villa González, R. (2000): "Primero datos sobre el Neolítico en Ciudad Real: la tumba de Villamayor de Calatrava". En L. Benítez de Lugo Enrich (coord.): El Patrimonio arqueológico de Ciudad Real. Métodos de trabajo y actuaciones recientes. Universidad Nacional de Educación a Distancia. Valdepeñas (Ciudad Real): 7-20.

Salazar-García, D.C.; Benítez de Lugo Enrich, L.; Álvarez, H.J. y Benito, M. (2013): "Estudio diacrónico de la dieta de los pobladores antiguos de Terrinches (Ciudad Real) a partir del análisis de isótopos estables sobre restos óseos humanos". Revista Española de Antropología Física, 34: 6-14.

Sánchez Meseguer, J.L. y Galán Saulnier, C. (2004): “El Cerro de La Encantada" en M.R. García Huerta y J. Morales Hervás coords. La Península Ibérica en el II milenio a.C.: poblados y fortificaciones. Universidad de Castilla-La Mancha. Cuenca: 115-172.

Torres Mas, M. (2015): "La motilla de El Azuer: un yacimiento de interés cultural en Daimiel (Ciudad Real). III Jornadas de Historia de Daimiel. Ayuntamiento de Daimiel. Daimiel: 31-44. 